\title{
Effect of Thermal Parameters on Hydration Heat Temperature and Thermal Stress of Mass Concrete
}

\author{
Yuqin Zhao, ${ }^{1}$ Gaosheng Li, ${ }^{1}$ Caixia Fan, ${ }^{1}$ Wentai Pang, ${ }^{2}$ and Yongtao Wang ${ }^{1}{ }^{1}$ \\ ${ }^{1}$ Institute of Transportation, Inner Mongolia University, Hohhot 010070, China \\ ${ }^{2}$ Inner Mongolia Water Resources and Hydropower Survey and Design Institute, Hohhot 010020, China \\ Correspondence should be addressed to Yongtao Wang; wyt_827@imu.edu.cn
}

Received 24 January 2021; Revised 10 February 2021; Accepted 18 February 2021; Published 3 March 2021

Academic Editor: Yanhu Mu

Copyright (c) 2021 Yuqin Zhao et al. This is an open access article distributed under the Creative Commons Attribution License, which permits unrestricted use, distribution, and reproduction in any medium, provided the original work is properly cited.

To explore the influence of concrete thermal parameters on the hydration heat temperature and thermal stress of mass concrete, four feature positions of a dam foundation were chosen to analyze the changing process of temperature and stress by varying the thermal parameters, including the thermal conductivity, specific heat, surface heat diffusion coefficient, temperature rise coefficient, solar absorption coefficient, and thermal expansion coefficient. Some conclusions were obtained as follows. Increasing the thermal conductivity and reducing the specific heat and temperature rise coefficient of concrete can effectively reduce the maximum temperature of the central concrete structure. Increasing the solar absorption coefficient, specific heat, and thermal expansion coefficient and reducing the thermal conductivity, surface heat diffusion coefficient, and temperature rise coefficient of concrete can reduce the maximum principal tensile stress in the structure to a certain extent. The maximum principal tensile stress at different positions of the structure has a linear functional relationship with the thermal conductivity, specific heat, and thermal expansion coefficient and has a quadratic function relationship with the surface heat diffusion coefficient, temperature rise coefficient, and solar absorption coefficient. Besides, this study also proposed a series of related anticracking measures. This study was expected to provide a theoretical reference for the design, construction, and cracking disease prevention of mass concrete structures.

\section{Introduction}

The large hydration heat can be produced in a short time during the casting of mass concrete structure, which leads to the rapid rise of the internal temperature of the mass concrete structure. Especially, the mass concrete structure is also affected by the external environment and the thermal parameters, which is easy to form a large thermal gradient and thermal stress between the core and the surface. As a result, cracks will occur when the thermal stress is larger than the tensile strength of the concrete. Therefore, temperature control is particularly important to the mass concrete [1]. To ensure the integrity and durability of mass concrete structure, the hydration heat temperature, thermal stress distribution, and influencing factors of mass concrete structure in the cold region are analyzed, and taken appropriate temperature control measures are the keys to construction organization design and comprehensive treatment of mass concrete structure diseases.

At present, some researchers have carried out lots of studies to analyze the temperature field, thermal stress, and influencing factors of mass concrete by using the finite element method and monitoring method. Some studies [2-9] found that the results of numerical calculation can accurately predict the distribution of temperature and stress of the structure by comparing with the field monitoring data, and it is feasible to put forward effective temperature control measures for the mass concrete structure according to the finite element simulation results by considering various influencing factors comprehensively at the design stage. So far, the influencing factors such as construction measures, amount and type of concrete material, and pipe cooling parameters have been studied. Reducing concrete casting temperature [10-14], changing casting date $[15,16]$, layered 
casting [17-19], and curing concrete [20, 21] can effectively reduce the maximum temperature of the structure. At the same time, changing insulation thickness [22] and types of insulation materials [23] has significant effects on the temperature difference and maximum tensile stress of the structure. The amount and type of concrete raw materials have a significant influence on the internal heat transfer and mechanical properties of concrete. High cement content [24-26] will make the temperature of the structure exceed the specified limit. Low temperature cement [27-29] can reduce the structure temperature and improve the crack resistance of the concrete structure. Additives [30-34] can also effectively reduce the temperature rise of cement hydration heat. The arrangement of cold water pipes is a very effective method to reduce the heat of hydration [35]. Controlling the inlet and outlet temperature of cooling water pipes, the spacing of cooling pipes, and adjusting the convection coefficient [36] between cooling water and concrete are effective measures to control the hydration heat of concrete. Meanwhile, medium-term temperature control and cooling [37] are also very important. Besides, Si et al. [38] also put forward a new idea that the small temperature difference cooling can effectively reduce the temperature gradient and thermal stress. In conclusion, these findings mainly focused on revealing the influence of construction design, amount and type of concrete raw materials, pipe cooling parameters on the hydration temperature, and thermal stress distribution of mass concrete. However, the thermal parameters are also closely related to the thermalmechanical characteristics of mass concrete structure, such as the thermal conductivity is a factor that directly affects the temperature gradient of the structure. Therefore, it is extremely important to study the influence of concrete thermal parameters on temperature and thermal stress distribution of mass concrete structure for crack control and disease treatment, especially for the mass concrete structure located in the cold region where the temperature changes greatly.

This study relied on Xiwugaigou Roller Compacted Concrete Dam Project in Inner Mongolia, China. A threedimensional finite element model considering hydration heat release, thermal parameters changing, and actual temperature boundary was built to analyze the maximum temperature, the temperature difference between the core and surface, and maximum principal tensile stress of the mass concrete aiming to study the influence of different values of thermal conductivity, specific heat, surface heat diffusion coefficient, temperature rise coefficient, solar absorption coefficient, and thermal expansion coefficient on the distribution of temperature and thermal stress at the core, surface, $50 \mathrm{~mm}$ from the surface, and foot of the concrete foundation. Furthermore, the functional relationship between different thermal parameters and the maximum principal tensile stress at different positions of the structure is determined. Finally, the study also puts forward a series of relevant crack prevention measures. The results will provide a theoretical basis for temperature control and crack prevention of mass concrete structures from the perspective of controlling the thermal properties of concrete materials.

\section{Basic Theory}

2.1. Heat Conduction Equation. For isotropic solids, the heat conduction equation considering concrete hydration heat is expressed as follows:

$$
\frac{\partial T}{\partial \tau}-\frac{\lambda}{c \rho} \nabla^{2} T=\frac{\partial \theta(\tau)}{\partial \tau},
$$

where $T$ is the temperature of the concrete, $\tau$ is the time, $\lambda$ is the thermal conductivity, $c$ is the specific heat, $\rho$ is the density of concrete, and $\theta(\tau)$ is the adiabatic temperature rise induced by hydration heat, which is calculated as follows:

$$
\theta(\tau)=\theta_{0}\left(1-e^{-m \tau}\right),
$$

where $\theta_{0}$ is the adiabatic temperature rise terminal value, and $m$ is the temperature rise coefficient.

\subsection{Implicit Expression of Unsteady Temperature Field.} Equation (1) becomes a matrix differential equation about the time after spatial discretization by the finite element method. The matrix differential equation is given as follows:

$$
[K]\{T\}+[C]\left\{\frac{\partial T}{\partial \tau}\right\}+\{R\}=0,
$$

where $[K]$ is the heat conduction matrix, $[C]$ is the heat capacity matrix, and $\{R\}$ is the thermal load vector. Assume $\tau=\tau_{i}$ corresponds to $T=T_{i}$ and $\tau=\tau_{i+1}$ corresponds to $T=T_{i+1}$; then,

$$
\begin{array}{r}
{[K]\left\{T_{i}\right\}+[C]\left\{\frac{\partial T}{\partial \tau}\right\}_{i}+\left\{R_{i}\right\}=0,} \\
{[K]\left\{T_{i+1}\right\}+[C]\left\{\frac{\partial T}{\partial \tau}\right\}_{i+1}+\left\{R_{i+1}\right\}=0,}
\end{array}
$$

$\Delta T_{i}$ can be defined as

$$
\Delta T_{i}=T_{i+1}-T_{i}=\Delta \tau_{i}\left(b\left\{\frac{\partial T}{\partial \tau}\right\}_{i+1}+(1-b)\left\{\frac{\partial T}{\partial \tau}\right\}_{i}\right) .
$$

Therefore,

$$
\left\{\frac{\partial T}{\partial \tau}\right\}_{i+1}=\frac{1}{b \Delta \tau_{\mathrm{i}}}\left[\left\{T_{i+1}\right\}-\left\{T_{i}\right\}\right]-\frac{1-b}{b}\left\{\frac{\partial T}{\partial \tau}\right\}_{i} .
$$

Substituting equation (5) in equation (4) obtains

$$
\begin{aligned}
& {[K]\left\{T_{i+1}\right\}+[C]\left(\frac{1}{b \Delta \tau_{\mathrm{i}}}\left[\left\{T_{i+1}\right\}-\left\{T_{i}\right\}\right]-\frac{1-b}{b}\left\{\frac{\partial T}{\partial \tau}\right\}_{i}\right)} \\
& +\left\{R_{i+1}\right\}=0 .
\end{aligned}
$$

So equation (4) becomes

$$
\begin{aligned}
\left([K]+\frac{1}{b \Delta \tau_{\mathrm{i}}}[C]\right)\left\{T_{i+1}\right\}= & -\left(\left(\frac{1-b}{b}\right)[K]-\frac{1}{b \Delta \tau_{\mathrm{i}}}[C]\right)\left\{T_{i}\right\} \\
& -\frac{1-b}{b}\left\{R_{i}\right\}-\left\{R_{i+1}\right\} .
\end{aligned}
$$


The temperature of each node at any time can be obtained by solving the equations. The parameter $b$ is usually taken as 1 in the calculation, which is the backward differential method.

\subsection{Finite Element Method for Elastic Creep Thermal Stress of} Concrete. Assume that concrete is an elasticity-creep solid. The thermal stress of concrete is calculated by the finite element method without considering the drying shrinkage of concrete [39]. In a three-dimensional space, the strain increment generated in $\Delta \tau_{n}=\tau_{n}-\tau_{n-1}$ can be expressed as follows:

$$
\left\{\Delta \varepsilon_{n}\right\}=\left\{\varepsilon\left(\tau_{n}\right)\right\}-\left\{\varepsilon\left(\tau_{n-1}\right)\right\}=\left\{\Delta \varepsilon_{n}^{e}\right\}+\left\{\Delta \varepsilon_{n}^{c}\right\}+\left\{\Delta \varepsilon_{n}^{T}\right\},
$$

where $\left\{\Delta \varepsilon_{n}\right\}$ is the strain increment, $\left\{\Delta \varepsilon_{n}^{e}\right\}$ is the elastic strain increment induced by the external force, $\left\{\Delta \varepsilon_{n}^{c}\right\}$ is the creep strain increment, and $\left\{\Delta \varepsilon_{n}^{T}\right\}$ is the temperature strain increment. The elastic strain increment is calculated as follows:

$$
\left\{\Delta \varepsilon_{n}^{e}\right\}=\frac{1}{E\left(\bar{\tau}_{n}\right)}[Q]\left\{\Delta \sigma_{n}\right\},
$$

where $\bar{\tau}_{n}$ is the median age of the concrete, equals to $\left(\left(\tau_{n}+\tau_{n-1}\right) / 2\right), E\left(\bar{\tau}_{n}\right)$ is the modulus of elasticity of the concrete at median age, $[Q]$ is a coefficient matrix, and $\left\{\Delta \sigma_{n}\right\}$ is the stress increment. The creep strain increment is calculated as follows:

$$
\left\{\Delta \varepsilon_{n}^{c}\right\}=\left\{\eta_{n}\right\}+C\left(t, \overline{\tau_{n}}\right)[Q]\left\{\Delta \sigma_{n}\right\},
$$

where $\left\{\eta_{n}\right\}$ is a matrix related to the creep coefficient, and $C\left(t_{n}, \bar{\tau}_{n}\right)$ is the specific creep of the concrete at median age.

Then, the relationship between stress increment and strain increment is given as follows:

$$
\left\{\Delta \sigma_{n}\right\}=\left[\bar{D}_{n}\right]\left(\left\{\Delta \varepsilon_{n}\right\}-\left\{\eta_{n}\right\}-\left\{\Delta \varepsilon_{n}^{T}\right\}\right),
$$

where $\left[\bar{D}_{n}\right]$ is the stress-strain matrix corresponding to $E\left(\bar{\tau}_{n}\right)$. The unit node force increment can be expressed as follows:

$$
\{\Delta F\}^{e}=\iiint[B]^{T}\left\{\Delta \sigma_{n}\right\} \mathrm{d} x \mathrm{~d} y \mathrm{~d} z
$$

where $\{\Delta F\}^{e}$ is the element nodal force increment, and $[B]^{T}$ is the transformation matrix of the deformation matrix $[B]$. The above formula can be written as follows:

$$
\{\Delta F\}^{e}=[k]^{e}\left\{\Delta \sigma_{n}\right\}^{e}-\iiint[B]^{T}\left[\bar{D}_{n}\right]\left(\left\{\eta_{n}\right\}+\left\{\Delta \varepsilon_{n}^{T}\right\}\right) \mathrm{d} x \mathrm{~d} y \mathrm{~d} z,
$$

where $[k]^{e}$ is the element stiffness matrix. Define

$$
\begin{aligned}
{[k]^{e} } & =\iiint[B]^{T}\left[\bar{D}_{n}\right][B] \mathrm{d} x \mathrm{~d} y \mathrm{~d} z,\left\{\Delta P_{n}\right\}_{e}^{c} \\
& =\iiint[B]^{T}\left[\bar{D}_{n}\right]\left\{\eta_{n}\right\} \mathrm{d} x \mathrm{~d} y \mathrm{~d} z,\left\{\Delta P_{n}\right\}_{e}^{T} \\
& =\iiint[B]^{T}\left[\bar{D}_{n}\right]\left\{\Delta \varepsilon_{n}^{T}\right\} \mathrm{d} x \mathrm{~d} y \mathrm{~d} z,
\end{aligned}
$$

where $\left\{\Delta P_{n}\right\}_{e}^{c}$ is the element node load increment by creep, and $\left\{\Delta P_{n}\right\}_{e}^{T}$ is the element node load increment by temperature. Therefore, the global balance equation is given as follows:

$$
[K]\left\{\Delta \sigma_{n}\right\}=\left\{\Delta P_{n}\right\}^{L}+\left\{\Delta P_{n}\right\}^{C}+\left\{\Delta P_{n}\right\}^{T},
$$

where $[K]$ is the global stiffness matrix, $\left\{\Delta P_{n}\right\}^{L}$ is the nodal load increment by external loads, $\left\{\Delta P_{n}\right\}^{C}$ is the node load increment by creep, and $\left\{\Delta P_{n}\right\}^{T}$ is the node load increment by temperature.

Finally, the stresses of each unit are as follows:

$$
\left\{\sigma_{n}\right\}=\sum\left\{\Delta \sigma_{n}\right\}
$$

\section{Methods}

The Xiwugaigou Reservoir Project, located in Inner Mongolia which is the typical cold region, consists of gravity dam, flood discharge, sand scouring tunnel, and diversion tunnel. According to the difference of materials, it can be divided into foundation section, water retaining section, overflow dam section, flood discharge, sand scouring tunnel section, diversion tunnel section, and joint parts. The maximum dam height is $43.4 \mathrm{~m}$, dam length is $224.0 \mathrm{~m}$, dam crest width is $5.0 \mathrm{~m}$, and the height of the foundation section located in the strong restraining from the area of the dam is $1-3 \mathrm{~m}$. To study the influence of concrete thermal parameters on hydration heat temperature and thermal stress of mass concrete, a three-dimensional finite element model of the dam foundation is established.

3.1. Finite Element Model. The highest foundation dam section with the size of $30 \mathrm{~m}$ (length) $* 20 \mathrm{~m}$ (width) $* 3 \mathrm{~m}$ (height) is chosen as the study object, which is located on the bedrock foundation, with the size of $40 \mathrm{~m}$ (length) $* 30 \mathrm{~m}$ (width) $* 5 \mathrm{~m}$ (height). As shown in Figure 1, four feature research points are setup to analyze the changing process of temperature and stress by varying the thermal parameters. Point $\mathrm{A}$ is located in the core of the structure, where the maximum temperature occurs. Point $B$ is located $50 \mathrm{~mm}$ away from the surface near the boundary area, which is the keypoint to calculate the temperature difference between the core and surface. Point $\mathrm{C}$ is located at the surface through which the surface temperature distribution of the structure can be observed directly. And point $\mathrm{D}$ is on the foot of the concrete structure which is one of the most prone stress concentration points. The boundary of the concrete foundation and bedrock is divided into $50 \mathrm{~mm}$ grids, and others are divided into $1.0 \mathrm{~m}$ grids in the model. The finite element model is shown in Figure 2.

3.2. Initial and Boundary Conditions. The initial placing temperature of concrete is taken as the initial temperature of concrete and foundation using the following calculation:

$$
T(x, y, z, 0)=T_{0}(x, y, z)=C(\text { constant }),
$$

where $T_{0}$ is the initial casting temperature of the concrete taken as $20^{\circ} \mathrm{C}$ in considering the actual project and construction experience. 


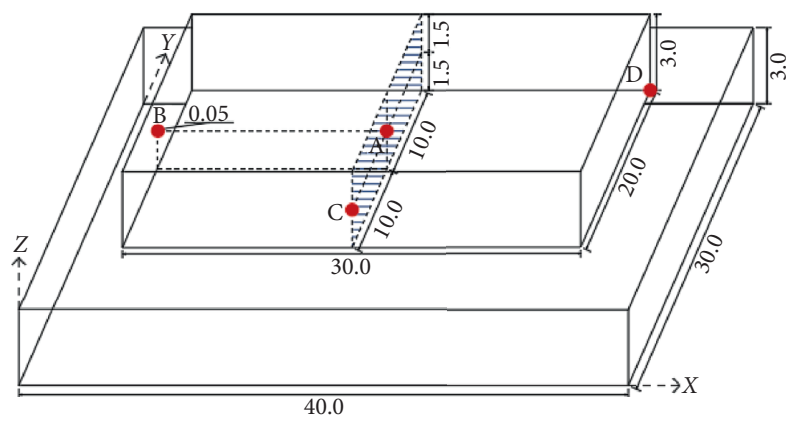

FIgURE 1: Main size and research points of the concrete foundation.

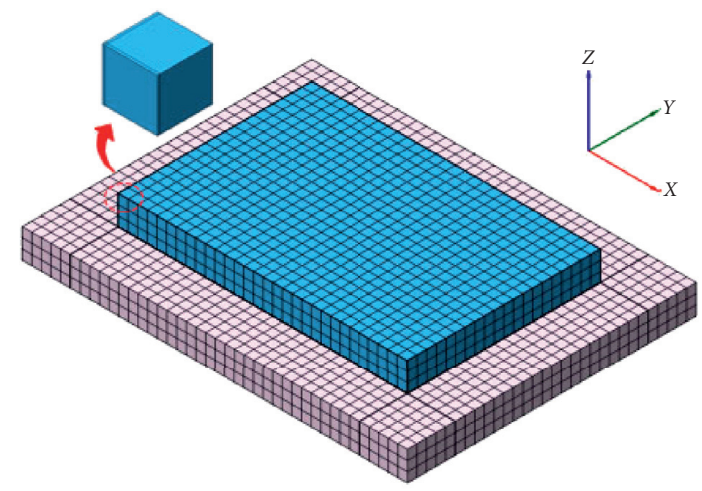

Figure 2: Mesh generation of the model.

In the calculation of the stress field, the boundary of the bedrock bottom is set as the fixed displacement constraint, the sides set as the normal displacement constraint, and the other sides of the model are the free surfaces. In the calculation of temperature field, the bottom and side of bedrock are set as the adiabatic boundaries, and the contact surface between bedrock and air and the surface between concrete and air are all set as the third boundary conditions, as shown in the following equation:

$$
-\lambda \frac{\partial T}{\partial n}=\beta\left(T-T_{a}\right)
$$

where $\beta$ is the surface heat diffusion coefficient. $T_{a}$ is the environment temperature, which is obtained by the monitoring data of the study area, and can be expressed by the following periodic function:

$$
T_{a}=4.5+17.95 \sin \left(\frac{2 \pi}{365} t+\frac{\pi}{25}\right)
$$

where $t$ is the time (day), $t=0$ corresponds to May $1^{\text {st }}, t=1$ corresponds to May $2^{\text {nd }}$, and so on. To intuitively see the temperature change of the project site, we present equation (20) in Figure 3. The curve shows that the project site is located in the cold region for negative temperature that occurs in the winter. The red part of the curve is the boundary temperature used in the modeling.

3.3. Parameters Data. The concrete is C20 normal concrete with the density of $2360 \mathrm{~kg} / \mathrm{m}^{3}$, the elastic modulus of $25.5 \mathrm{GPa}$, and Poisson's ratio of 0.167 . The adiabatic

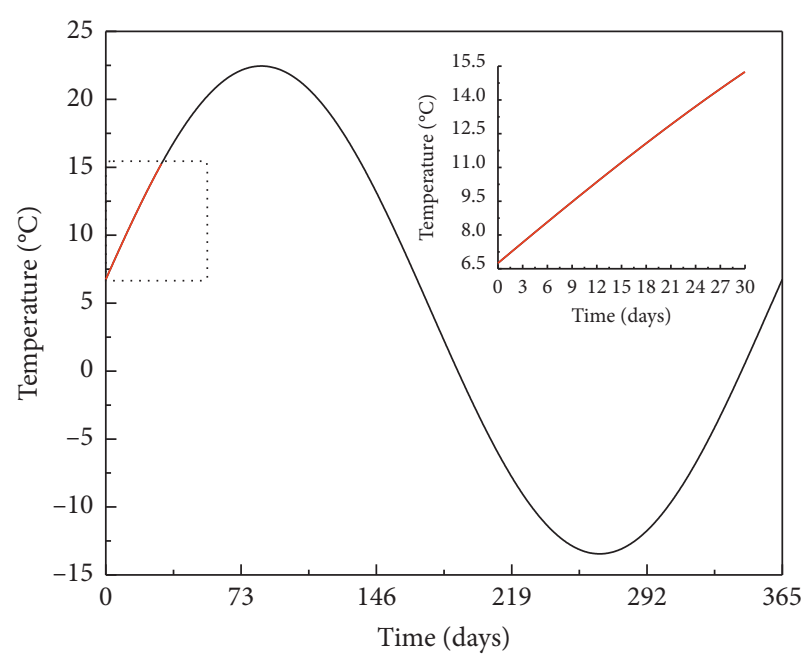

FIGURE 3: Environment temperature change of the project site.

temperature rise of concrete is calculated by equation (2), and the final value of temperature rise is $30^{\circ} \mathrm{C}$. The parameters of bedrock are shown in Table 1.

The main parameters influencing the thermal performance of concrete are thermal conductivity, specific heat, temperature rise coefficient, surface heat diffusion coefficient, solar absorption coefficient, and thermal expansion coefficient $[40,41]$. These parameters are the basic data for solving the thermal stress caused by the temperature change inside the concrete structure, which mainly depends on the concrete age, aggregate type, cement type, water-cement ratio, unit weight, and temperature. Therefore, thermal parameters are explored as variables in this study. The values of each thermal parameter are shown in Table 2, which cover the possible range in the construction [41, 42].

3.4. Temperature Control Requirements. When the thermal stress exceeds the bearing limit of concrete, the structure will be broken, resulting in thermal cracks. According to the Chinese standard for construction of mass concrete [43], the maximum temperature of the foundation should not exceed $70^{\circ} \mathrm{C}$, the temperature difference between the core and surface should not exceed $25^{\circ} \mathrm{C}$, and the allowable principal tensile stress of the concrete is $2.45 \mathrm{MPa}$ at the age of 28 days of concrete.

\section{Results and Discussion}

Based on the concrete foundation model, the influence of each thermal parameter on the maximum temperature, the temperature difference between the core and surface, and maximum principal tensile stress of mass concrete are analyzed by using the control variate method.

4.1. Effect of Thermal Conductivity. Figure 4 shows the relationship of temperature over time with four different thermal conductivities, which are $0.5 \mathrm{~W} /(\mathrm{m} \cdot \mathrm{K}), 1.5 \mathrm{~W} /$ $(\mathrm{m} \cdot \mathrm{K}), \quad 2.5 \mathrm{~W} /(\mathrm{m} \cdot \mathrm{K})$, and $3.5 \mathrm{~W} /(\mathrm{m} \cdot \mathrm{K})$, respectively. As shown in Figure 4, the temperature of point $A$ at the 
TABLe 1: Basic parameters of bedrock.

\begin{tabular}{lcccccc}
\hline Material & $\begin{array}{c}\text { Density } \\
\mathrm{kg} / \mathrm{m}^{3}\end{array}$ & $\begin{array}{c}\text { Elastic modulus } \\
\mathrm{GPa}\end{array}$ & $\begin{array}{c}\text { Thermal conductivity } \\
\mathrm{W} /(\mathrm{m} \cdot \mathrm{K})\end{array}$ & $\begin{array}{c}\text { Specific heat } \\
\mathrm{kJ} /\left(\mathrm{kg} \cdot{ }^{\circ} \mathrm{C}\right)\end{array}$ & $\begin{array}{c}\text { Thermal expansion coefficient } \\
* 10^{-6} /{ }^{\circ} \mathrm{C}\end{array}$ & Poisson's ratio \\
\hline Bedrock & 2800 & 35 & 2.91 & 0.72 & 8.5 \\
\hline
\end{tabular}

TABLE 2: Values of various thermal parameters under different conditions.

\begin{tabular}{|c|c|c|c|c|c|c|}
\hline Conditions & $\begin{array}{c}\text { Thermal } \\
\text { conductivity } \\
\lambda \\
\mathrm{W} /(\mathrm{m} \cdot \mathrm{K})\end{array}$ & $\begin{array}{c}\text { Specific } \\
\text { heat } \\
c \\
\mathrm{~kJ} /\left(\mathrm{kg} \cdot{ }^{\circ} \mathrm{C}\right)\end{array}$ & $\begin{array}{c}\text { Surface heat diffusion } \\
\text { coefficient } \\
\beta \\
\mathrm{kJ} /\left(\mathrm{m}^{2} \cdot \mathrm{h} \cdot{ }^{\circ} \mathrm{C}\right)\end{array}$ & $\begin{array}{c}\text { Temperature rise } \\
\text { coefficient } \\
m \\
\mathrm{~d}^{-1}\end{array}$ & $\begin{array}{c}\text { Solar absorption } \\
\text { coefficient } \\
r \\
-\end{array}$ & $\begin{array}{c}\text { Thermal expansion } \\
\text { coefficient } \\
\alpha \\
* 10^{-6} /{ }^{\circ} \mathrm{C}\end{array}$ \\
\hline 1 & $0.5 \sim 3.5$ & 1 & 50 & 0.3 & 0 & 10 \\
\hline 2 & 1 & $0.8 \sim 1.2$ & 50 & 0.3 & 0 & 10 \\
\hline 3 & 1 & 1 & $18.46 \sim 165.13$ & 0.3 & 0 & 10 \\
\hline 4 & 1 & 1 & 50 & $0.2 \sim 0.4$ & 0 & 10 \\
\hline 5 & 1 & 1 & 50 & 0.3 & $0.4 \sim 0.8$ & 10 \\
\hline 6 & 1 & 1 & 50 & 0.3 & 0 & $8 \sim 12$ \\
\hline
\end{tabular}

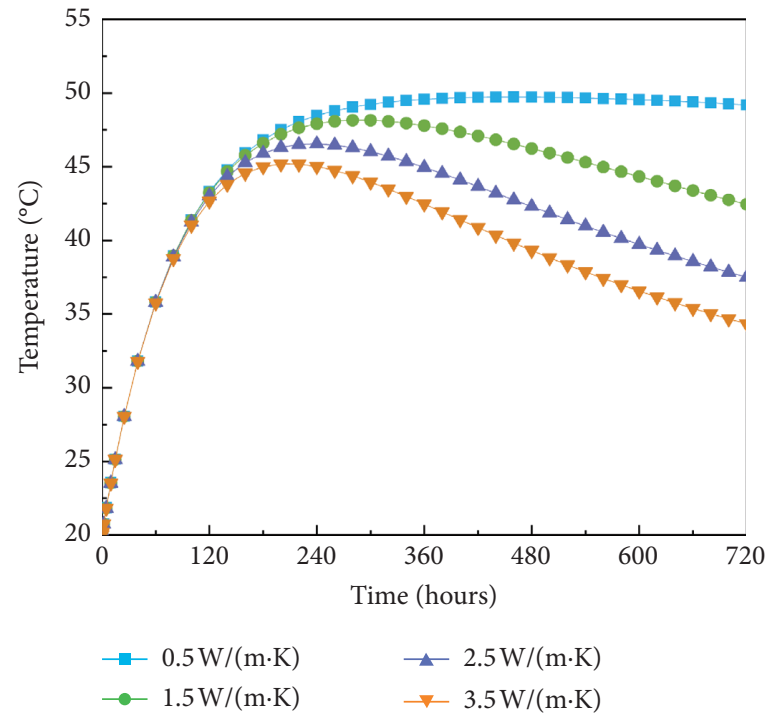

(a)

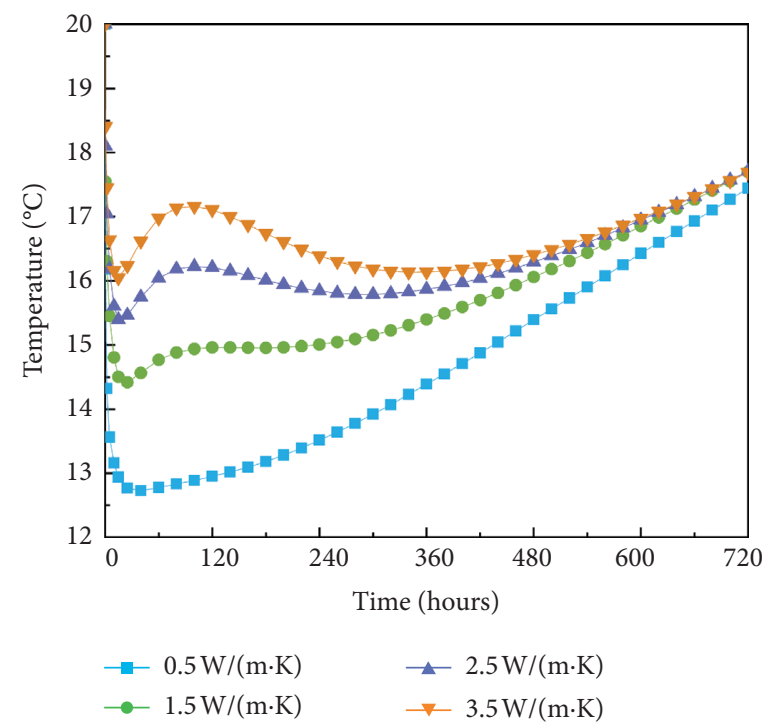

(c)

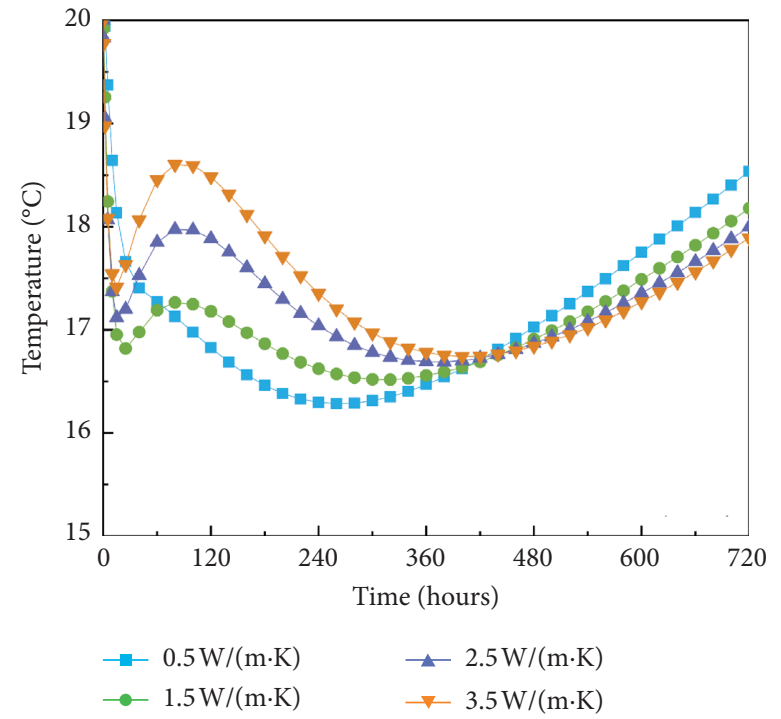

(b)

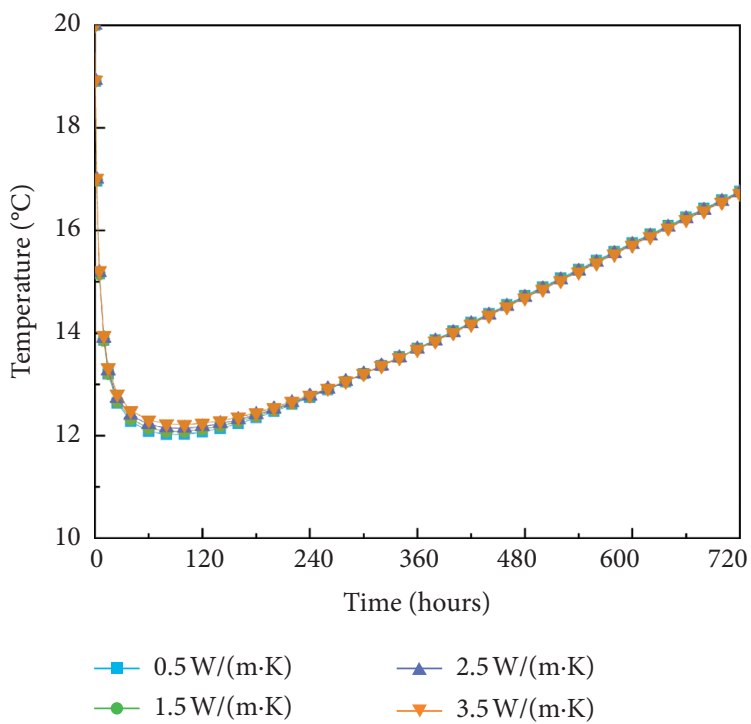

(d)

Figure 4: Temperature-time curves with different thermal conductivities. (a) Point A, (b) point B, (c) point C, and (d) point D. 
structure core with different thermal conductivities demonstrates a tendency to rise rapidly and then decrease slowly. The maximum temperature of point $\mathrm{A}$ is $49.7^{\circ} \mathrm{C}, 48.2^{\circ} \mathrm{C}$, $46.6^{\circ} \mathrm{C}$, and $45.5^{\circ} \mathrm{C}$ correspondingly, all appeared at about 240 hours. The temperature of point B located at $50 \mathrm{~mm}$ inside the surface demonstrates a twice process of decrease to increase. After 420 hours, the temperature of point B with bigger thermal conductivity is lower than one with a smaller one. The temperature of surface point $\mathrm{C}$ demonstrates a similar change process with point $B$, but with smaller amplitude. However, the temperature of point $\mathrm{C}$ in different thermal conductivity changes to the same value that almost equals to the environment temperature. The temperature at point $\mathrm{D}$ at the foot of the concrete structure is almost keeping the same change process at different thermal conductivities because it is mainly determined by the environment temperature. At the same time, the temperature difference between the core and surface of the structure is calculated as $33.1^{\circ} \mathrm{C}, 31.6^{\circ} \mathrm{C}, 29.7^{\circ} \mathrm{C}$, and $28.0^{\circ} \mathrm{C}$, respectively. From the above analysis, it can be found that the hydration heat has the strongest heating effect in the core region of the structure. The heat is mainly released close to the concrete surface. However, increasing the thermal conductivity of concrete has a positive effect on the thermal stability of the construction for reducing the maximum temperature in the core region of the structure and also decreasing the temperature difference between the core and surface of the concrete foundation.

Figure 5 shows the calculated and fitted maximum principal tensile stress at each point with a different thermal conductivity. The principal tensile stress is induced by the action of temperature and self-weight. Due to symmetry, the maximum principal tensile stress of point $\mathrm{A}$ is close to zero. Due to the stress relief, the maximum principal tensile stresses at points $\mathrm{B}$ and $\mathrm{C}$ is all less than allowable principal tensile stress, while the maximum principal tensile stress occurs at point D. Point D is located at the junction of the bedrock, and the structure and the displacement is restrained at the same time; as a result, stress concentration is easy to occur, but it cannot be eliminated in construction. Therefore, more attention should be paid to the maximum principal tensile stress in this region. Moreover, as shown in Figure 4, the maximum principal tensile stress at points $\mathrm{A}, \mathrm{B}$, and $C$ decreases, while point $D$ increases with the increase of thermal conductivity. Fitting the maximum principal tensile stress of four points with the thermal conductivity shows a linear relationship with the maximum principal tensile stress of the structure and positive correlation in points $\mathrm{A}, \mathrm{B}$, and $\mathrm{C}$ while negative correlation in point D. Obviously, the tensile stress of concrete interior can be reduced through increasing the thermal conductivity of concrete, and the situation is just opposite in the junction of the bedrock and the structure. Anyway, the maximum principal tensile stress inside the construction does not exceed the tensile strength of concrete with every thermal conductivity. On the contrary, the maximum principal tensile stress is larger than the tensile strength of concrete when the thermal conductivity is bigger than $1.0 \mathrm{~W} /(\mathrm{m} \cdot \mathrm{K})$, which can cause structural cracks. The maximum principal tensile stress increases $36.7 \%$ when the thermal conductivity changes from $0.5 \mathrm{~W} /(\mathrm{m} \cdot \mathrm{K})$ to $3.5 \mathrm{~W} /$ $(\mathrm{m} \cdot \mathrm{K})$. In conclusion, reducing the thermal conductivity of concrete can reduce the risk of structural cracking.

Therefore, suitable thermal conductivity not only ensures the temperature below the standard threshold but also makes sure the stress state under stable. Some research results $[44,45]$ can be used to realize this target, such as using limestone, lightweight aggregate (expanded shale), recycled, or natural and recycled aggregates to replace basalt, quartzite, siltstone, and other coarse aggregates, adding auxiliary cementitious materials (fly ash and slag) and not too high humidity during casting.

4.2. Effect of Specific Heat. Figure 6 shows the relationship between temperature and time with four different specifics heat which are $0.8 \mathrm{~kJ} /\left(\mathrm{kg} .{ }^{\circ} \mathrm{C}\right), 0.9 \mathrm{~kJ} /\left(\mathrm{kg} \cdot{ }^{\circ} \mathrm{C}\right), 1.0 \mathrm{~kJ} /\left(\mathrm{kg} \cdot{ }^{\circ} \mathrm{C}\right)$, and $1.1 \mathrm{~kJ} /\left(\mathrm{kg} .{ }^{\circ} \mathrm{C}\right)$, respectively. As shown in Figure 6 , the temperature of the four points demonstrates the same change process similar to themselves with different thermal conductivities, as shown in Figure 4. Besides, the temperature rises more with bigger specific heat than that with smaller specific heat. However, the temperature differences with the different specifics heat of the same point are smaller than that with different thermal conductivities, which proposed that thermal conductivity has a greater influence on the temperature than specific heat. The maximum temperature of point $\mathrm{A}$ is $48.5^{\circ} \mathrm{C}, 48.8^{\circ} \mathrm{C}, 49.0^{\circ} \mathrm{C}, 49.2^{\circ} \mathrm{C}$, and $49.3^{\circ} \mathrm{C}$, respectively. The maximum temperature of the first temperature rise at point $\mathrm{B}$ is $16.3^{\circ} \mathrm{C}, 16.6^{\circ} \mathrm{C}, 17.0^{\circ} \mathrm{C}, 17.3^{\circ} \mathrm{C}$, and $17.6^{\circ} \mathrm{C}$, appeared around 80 hours. The maximum temperature of the first temperature rise at point $\mathrm{C}$ is $13.7^{\circ} \mathrm{C}$, $13.9^{\circ} \mathrm{C}, 14.1^{\circ} \mathrm{C}, 14.3^{\circ} \mathrm{C}$, and $14.4^{\circ} \mathrm{C}$, also appeared around 80 hours. The temperature at point $\mathrm{D}$ is almost keeping the same change process with the environment temperature, basically not affected by specific heat. At the same time, the temperature difference between the core and surface of the structure is calculated as $32.7^{\circ} \mathrm{C}, 32.6^{\circ} \mathrm{C}, 32.5^{\circ} \mathrm{C}, 32.4^{\circ} \mathrm{C}$, and $32.3^{\circ} \mathrm{C}$, respectively, with each specific heat. Obviously, reducing the specific heat can reduce the maximum temperature inside the structure, but increase the temperature difference between the core and surface of the structure. However, the temperature change is very limited, especially when compared with the change brought about by thermal conductivity.

Figure 7 shows the calculated and fitted maximum principal tensile stress at each point with a different specific heat. The maximum principal tensile stress of point $A$ is close to zero and points $\mathrm{B}$ and $\mathrm{C}$ are all less than allowable principal tensile stress, and the maximum principal tensile stress occurs at point $\mathrm{D}$ for the same reason discussed in Section 4.1. Moreover, as shown in Figure 6, the maximum principal tensile stress at points $A, B$, and $C$ increases while point $\mathrm{D}$ decreases with the increases of specific heat, all change with a linear relationship. Therefore, increasing the specific heat can reduce the maximum principal tensile stress of the construction. The maximum principal tensile stress reduces $6.8 \%$ when the specific heat increases from $0.8 \mathrm{~kJ} /$ $\left(\mathrm{kg} .{ }^{\circ} \mathrm{C}\right)$ to $1.1 \mathrm{~kJ} /\left(\mathrm{kg} \cdot{ }^{\circ} \mathrm{C}\right)$. 


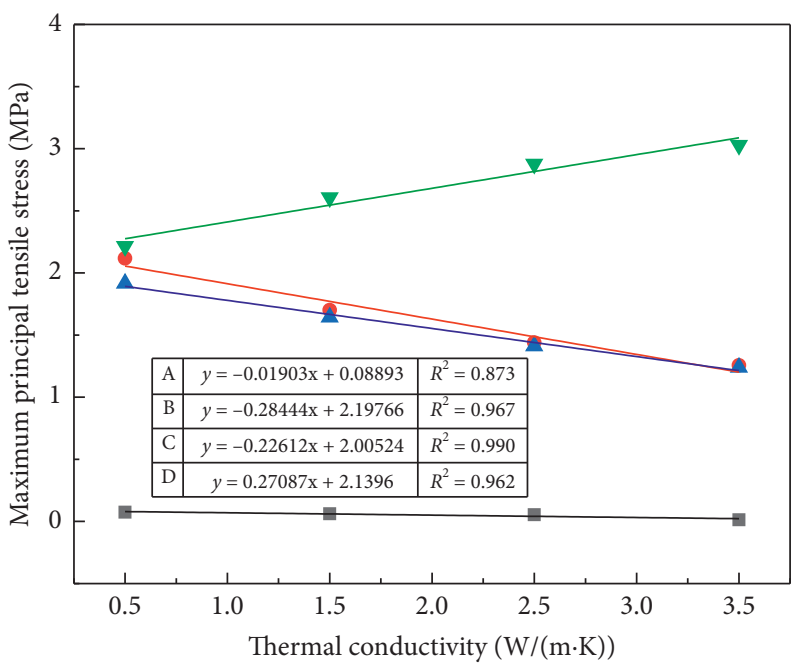

$\begin{array}{ll}\text { Calculated values } & \text { Fitted values } \\ \text { - A } & -\mathrm{A} \\ \text { - B } & -\mathrm{B} \\ \text { A C } & -\mathrm{C} \\ \nabla \mathrm{D} & -\mathrm{D}\end{array}$

Figure 5: The calculated and fitted maximum principal tensile stress at each point with a different thermal conductivity.

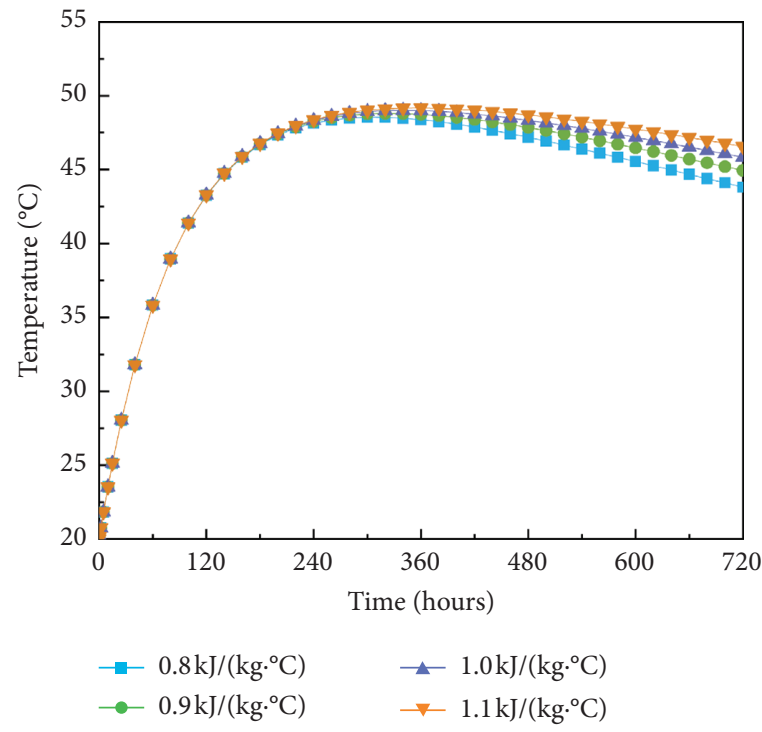

(a)

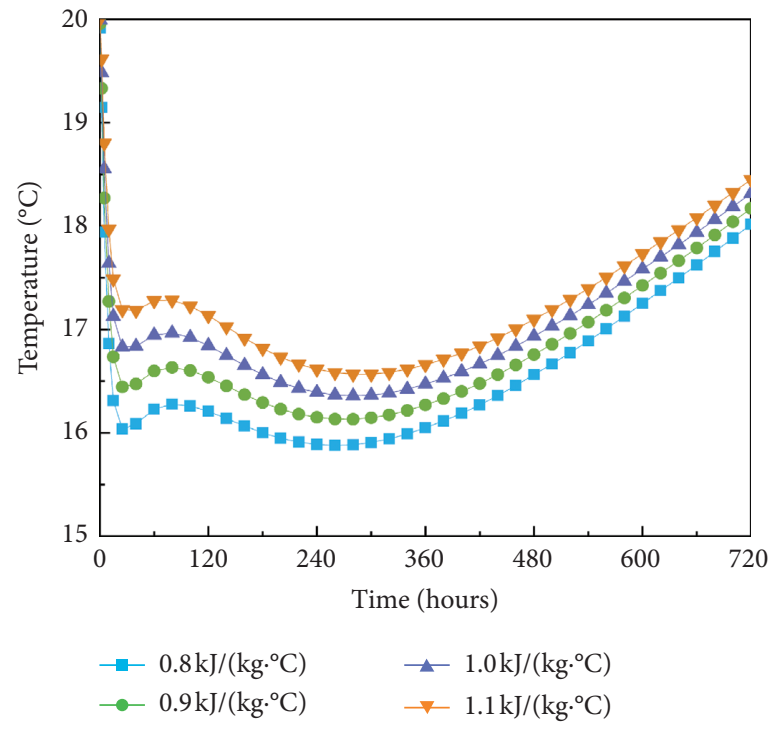

(b)

Figure 6: Continued. 


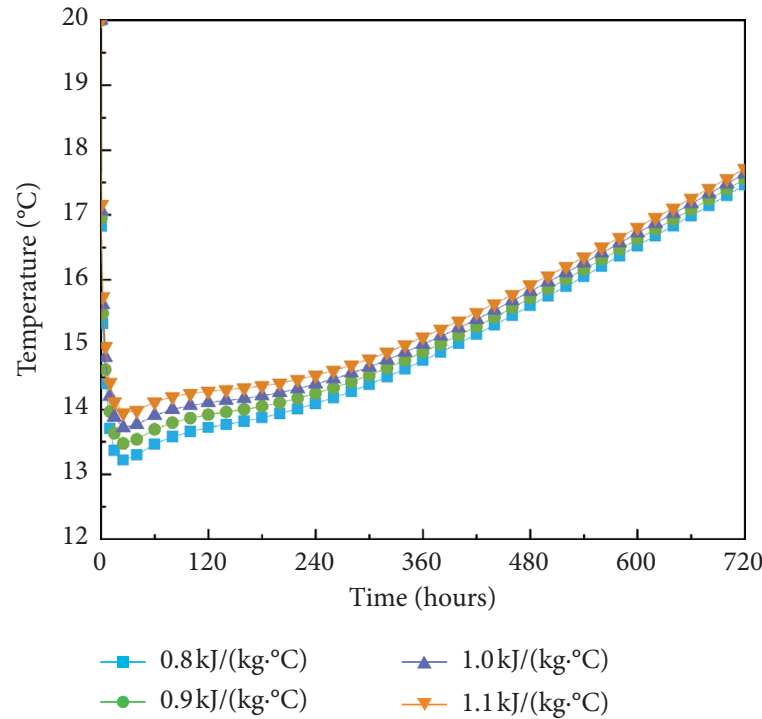

(c)

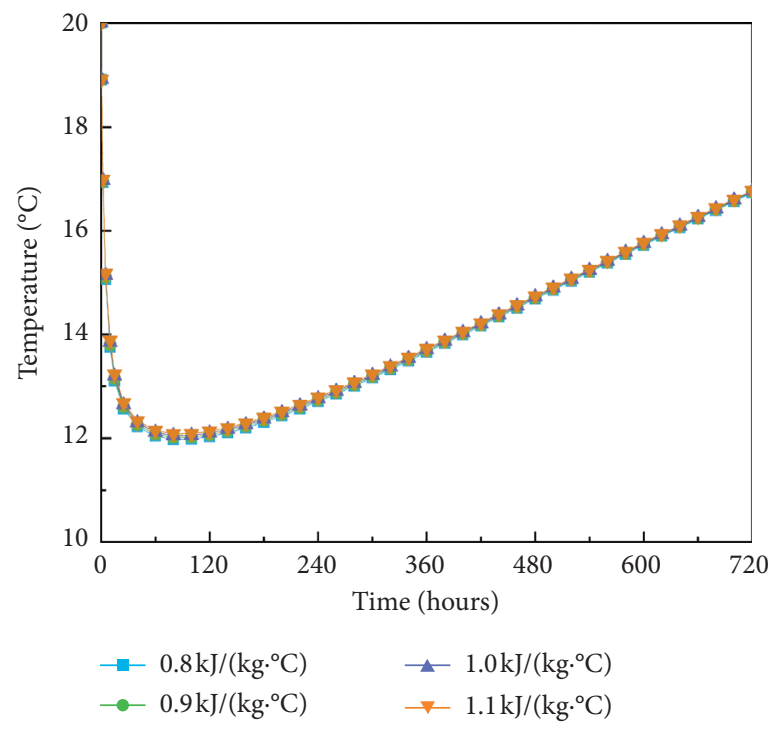

(d)

Figure 6: Temperature-time curves with different specifics heat. (a) Point A, (b) point B, (c) point C, and (d) point D.

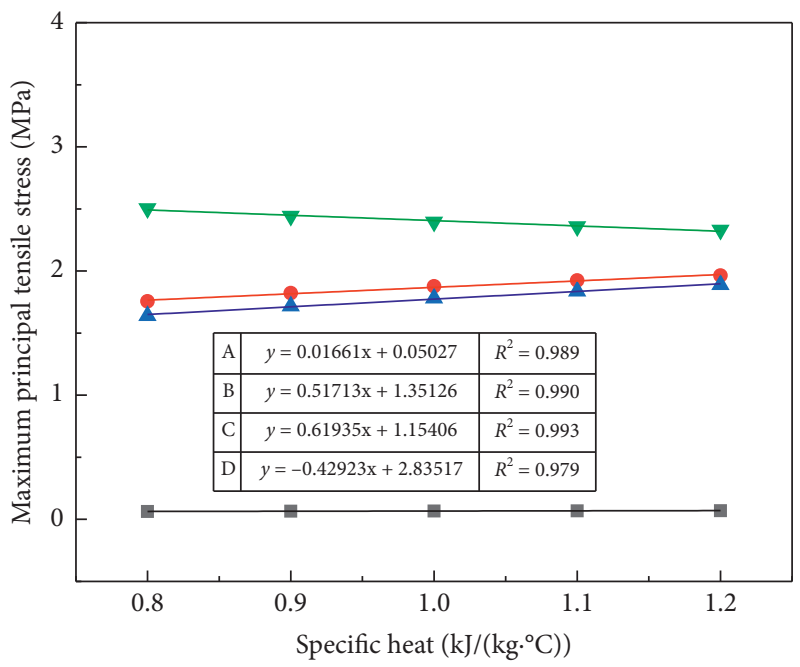

$\begin{array}{ll}\text { Calculated values } & \text { Fitted value } \\ \text { - A } & -\mathrm{A} \\ \text { - B } & -\mathrm{B} \\ \text { A C } & -\mathrm{C} \\ \nabla \text { D } & -\mathrm{D}\end{array}$

Figure 7: The calculated and fitted maximum principal tensile stress at each point with a different specific heat.

In conclusion, specific heat increase has a positive effect on hydration temperature rise and a negative effect on maximum principal tensile stress. However, the influence of concrete specific heat on the maximum principal tensile stress is greater than that on the maximum temperature. Under the condition that the hydration heat temperature meets the requirements, it enlightens us to control the maximum principal tensile stress to avoid the structure cracking through increasing specific heat methods, such as adding an appropriate amount of fly ash and slag, reasonably reducing the sand ratio, appropriately increasing the content of small stones under the condition of constant coarse aggregate gradation [46].

4.3. Effect of Surface Heat Diffusion Coefficient. Figure 8 shows the relationship between temperature and time with four different surface heat diffusion coefficients which are $18 \mathrm{~kJ} /\left(\mathrm{m}^{2} \cdot \mathrm{h} \cdot{ }^{\circ} \mathrm{C}\right), 78 \mathrm{~kJ} /\left(\mathrm{m}^{2} \cdot \mathrm{h} \cdot{ }^{\circ} \mathrm{C}\right), 138 \mathrm{~kJ} /\left(\mathrm{m}^{2} \cdot \mathrm{h} \cdot{ }^{\circ} \mathrm{C}\right)$, and $165 \mathrm{~kJ} /\left(\mathrm{m}^{2} \cdot \mathrm{h} \cdot{ }^{\circ} \mathrm{C}\right)$, respectively. It can be seen that the surface heat diffusion coefficient has no obvious influence on the temperature in the central concrete structure, such as point 


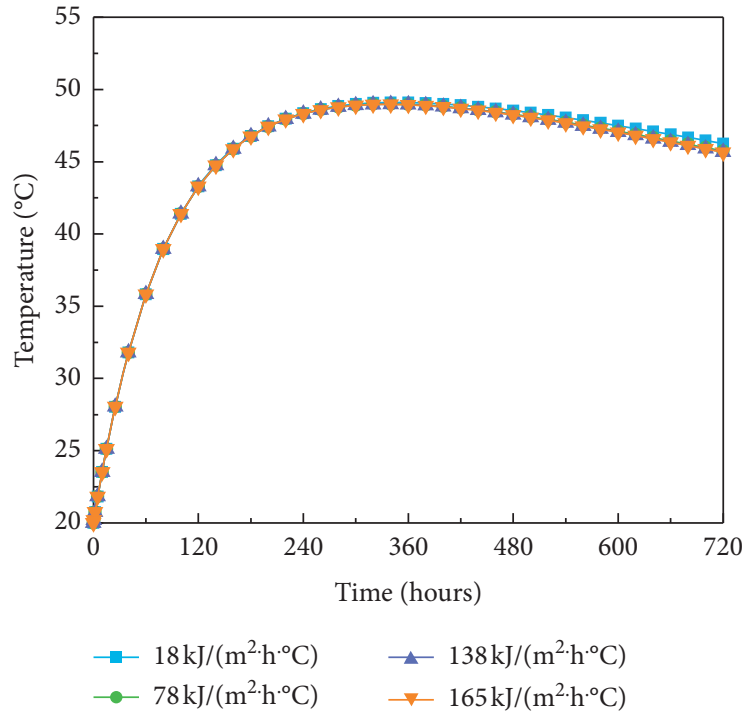

(a)

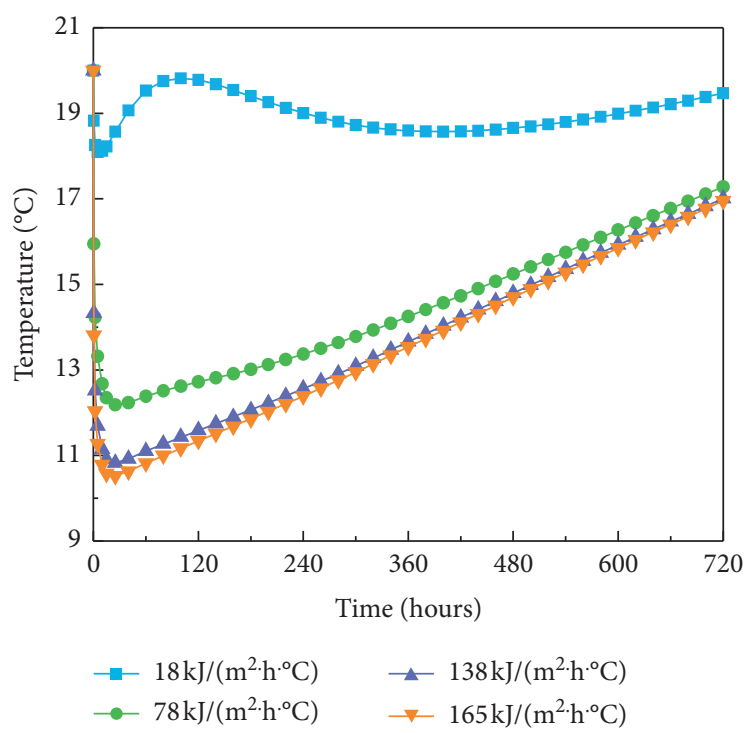

(c)

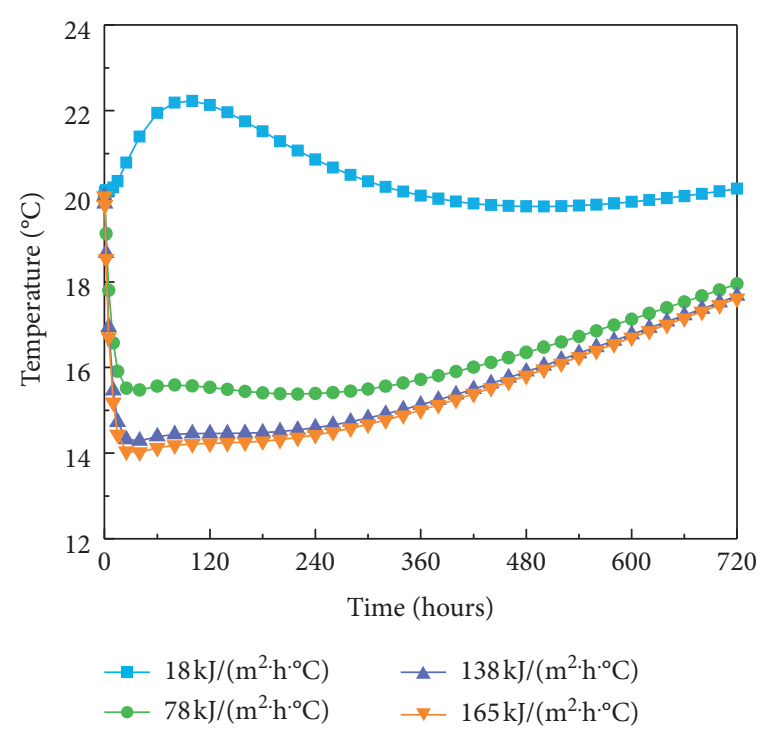

(b)

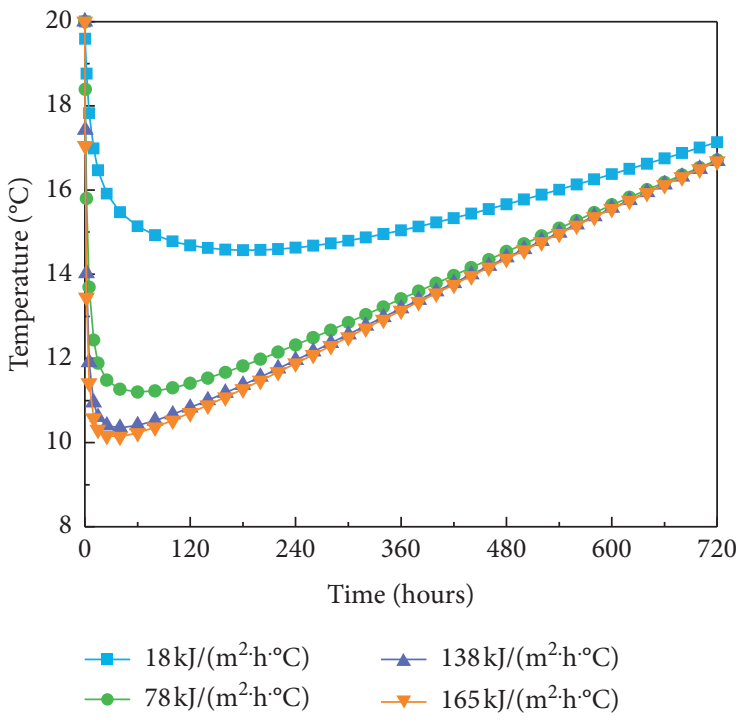

(d)

Figure 8: Temperature-time curves with different surface heat diffusion coefficients. (a) Point A, (b) point B, (c) point C, and (d) point D.

A. The temperature rise in the central concrete structure is mainly controlled by the thermal conductivity and specific heat. However, the surface heat diffusion coefficient has a more significant impact near the boundary of the structure. As shown in Figure 8, there is an obvious hydration heat temperature rise at points $\mathrm{B}$ and $\mathrm{C}$ when the surface heat diffusion coefficient equals $18 \mathrm{~kJ} /\left(\mathrm{m} 2 \cdot \mathrm{h} \cdot{ }^{\circ} \mathrm{C}\right)$. The temperature is easily affected by environmental temperature along with the increase of the surface heat diffusion coefficient. The maximum temperature of point $\mathrm{A}$ is close to $49.0^{\circ} \mathrm{C}$ appeared at 340 hours with a different surface heat diffusion coefficient. The temperature difference between the core and surface is $29.0^{\circ} \mathrm{C}, 33.4^{\circ} \mathrm{C}, 34.0^{\circ} \mathrm{C}$, and $34.1^{\circ} \mathrm{C}$, respectively, with each surface heat diffusion coefficient. Therefore, a bigger surface heat diffusion coefficient contributes to more heat loss in the boundary, but it is not conducive to reduce the temperature difference between the core and surface.

Figure 9 shows the calculated and fitted maximum principal tensile stress at each point with the different surface heat diffusion coefficient. The maximum principal tensile stress of point $\mathrm{A}$ is close to zero due to symmetry. The maximum principal tensile stress of points $B$ and $C$ decreases with the surface heat diffusion coefficient increase because that more temperature stress is relieved with a bigger surface heat diffusion coefficient. However, because point D is constrained by the bedrock, the temperature stress cannot be easily relieved with heat loss, so the maximum principal tensile stress shows an increasing trend with the surface heat diffusion coefficient increase. The maximum principal tensile stress at four points all shows a law of quadratic function. 


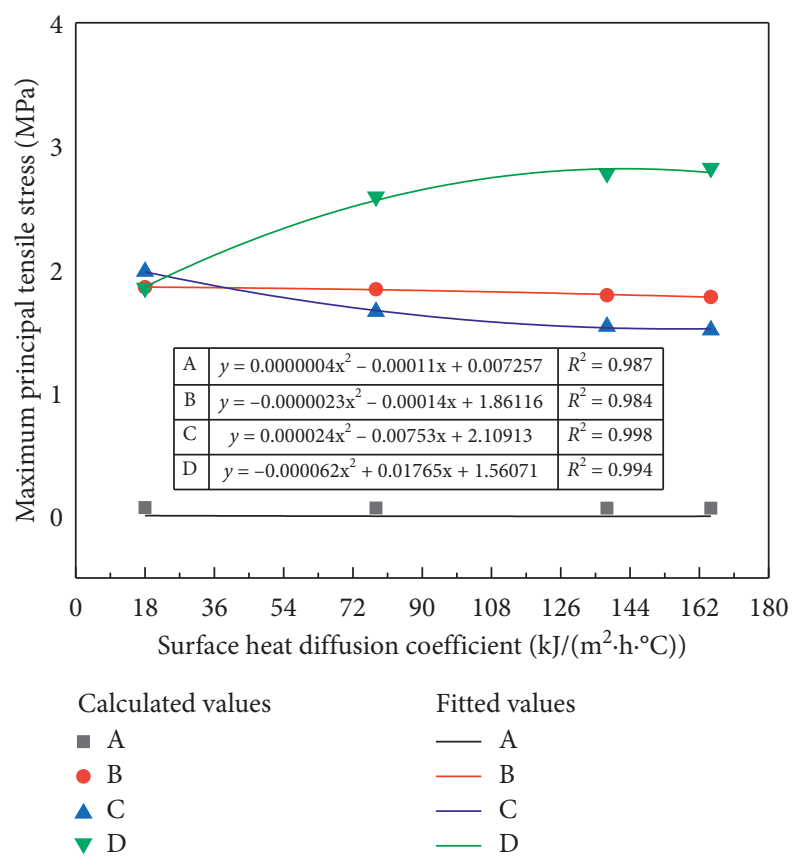

Figure 9: The calculated and fitted maximum principal tensile stress at each point with a different surface heat diffusion coefficient.

In conclusion, appropriately reducing the surface heat diffusion coefficient has a positive effect on relieving the maximum principal tensile stress. The maximum principal tensile stress reduces up to $52 \%$ when the surface heat diffusion coefficient changes from $165 \mathrm{~kJ} /\left(\mathrm{m}^{2} \cdot \mathrm{h} \cdot{ }^{\circ} \mathrm{C}\right)$ to $8 \mathrm{~kJ} /\left(\mathrm{m}^{2} \cdot \mathrm{h} \cdot{ }^{\circ} \mathrm{C}\right)$. Since the surface heat diffusion coefficient is related to wind speed, surface roughness, and surface thermal resistance condition [47], measures such as surface insulation, adding additives (such as defoamer) can be taken to reduce the surface heat diffusion coefficient and finally reduce the maximum principal tensile stress and prevent the occurrence of structural thermal cracks.

4.4. Effect of Temperature Rise Coefficient. Figure 10 shows the relationship between temperature and time with five different temperature rise coefficients which are $0.20 \mathrm{~d}^{-1}$, $0.25 \mathrm{~d}^{-1}, 0.30 \mathrm{~d}^{-1}, 0.35 \mathrm{~d}^{-1}$, and $0.40 \mathrm{~d}^{-1}$, respectively. It can be seen that the temperature rise coefficient has a significant impact on the first hydration heat temperature rise process whether in the core region or near the boundary of the structure, except for the foot point $\mathrm{D}$. The maximum temperature of point $\mathrm{A}$ is $48.2^{\circ} \mathrm{C}, 48.7^{\circ} \mathrm{C}, 49.0^{\circ} \mathrm{C}, 49.2^{\circ} \mathrm{C}$, and $49.4^{\circ} \mathrm{C}$, respectively, appeared at 420 hours, 380 hours, 340 hours, 320 hours, and 280 hours with the corresponding temperature rise coefficient. The temperature difference between the core and surface is $31.3{ }^{\circ} \mathrm{C}, 32.1^{\circ} \mathrm{C}, 32.6^{\circ} \mathrm{C}$, $32.9^{\circ} \mathrm{C}$, and $33.2^{\circ} \mathrm{C}$, respectively. It is obvious that reducing the temperature rise coefficient can reduce the maximum temperature and also reduce the temperature difference between the core and surface of the structure by changing the rate of temperature rise in the condition of the same hydration heat generated.
Figure 11 shows the calculated and fitted maximum principal tensile stress at each point with a different temperature rise coefficient. The maximum principal tensile stress of four points with a different temperature rise coefficient shows a similar change regulation with that with a different surface heat diffusion coefficient, and the maximum principal tensile stress at four points also shows a law of quadratic function with the temperature rise coefficient. The foot points of the structure, including point $\mathrm{D}$, are also the positions of stress concentration and the maximum principal tensile stress which has exceeded the allowable stress of the concrete if the temperature rise coefficient is greater than $0.30 \mathrm{~d}^{-1}$.

In conclusion, appropriate decrease of the temperature rise coefficient has a positive effect on relieving the maximum principal tensile stress. The maximum principal tensile stress can reduce $18.9 \%$ when the temperature rise coefficient changes from $0.40 \mathrm{~d}^{-1}$ to $0.20 \mathrm{~d}^{-1}$. Measures such as controlling pouring temperature and reducing the amount of cement [48] can be taken to reduce the temperature rise coefficient and decrease the maximum principal tensile stress in the result.

4.5. Effect of Solar Absorption Coefficient. The thermal parameters analyzed above have not considered the influence of the solar absorption coefficient, which was set to zero. However, studies $[42,49]$ found that the temperature field of the concrete structure is greatly affected by solar radiation. When calculating the radiant heat of the flat surface of a concrete structure, the annual variation of radiant heat $\Delta F$ and the annual average radiant heat $\Delta \bar{T}[1]$ are usually calculated as follows: 


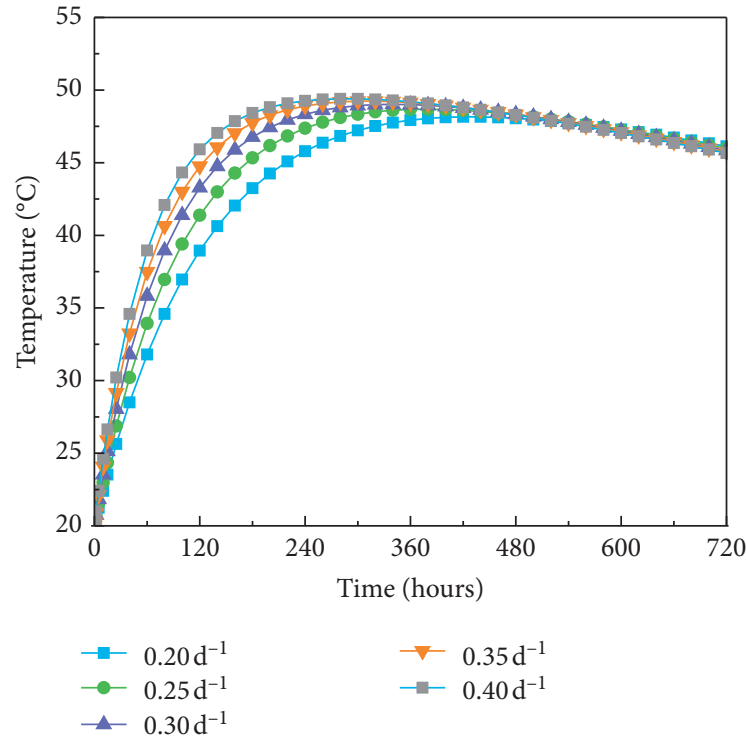

(a)

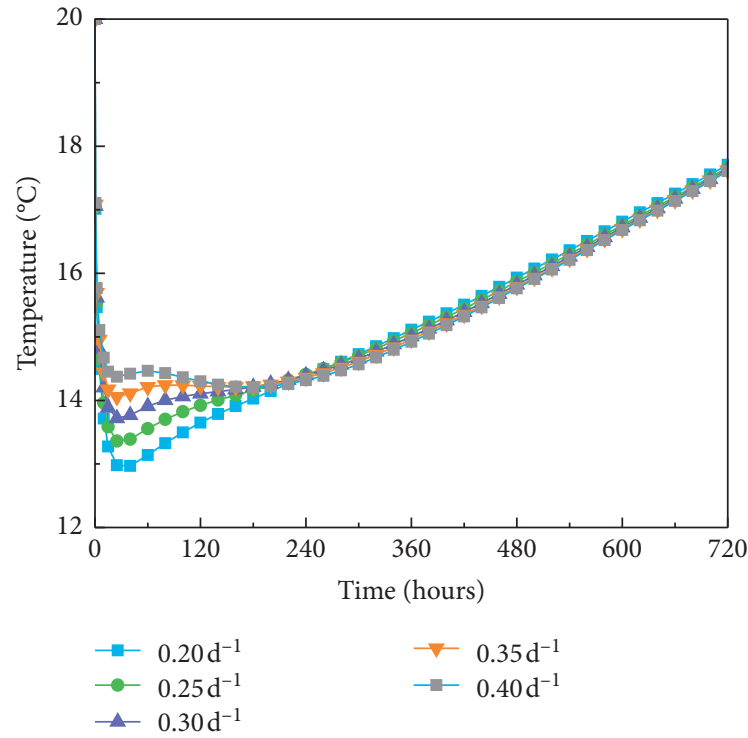

(c)

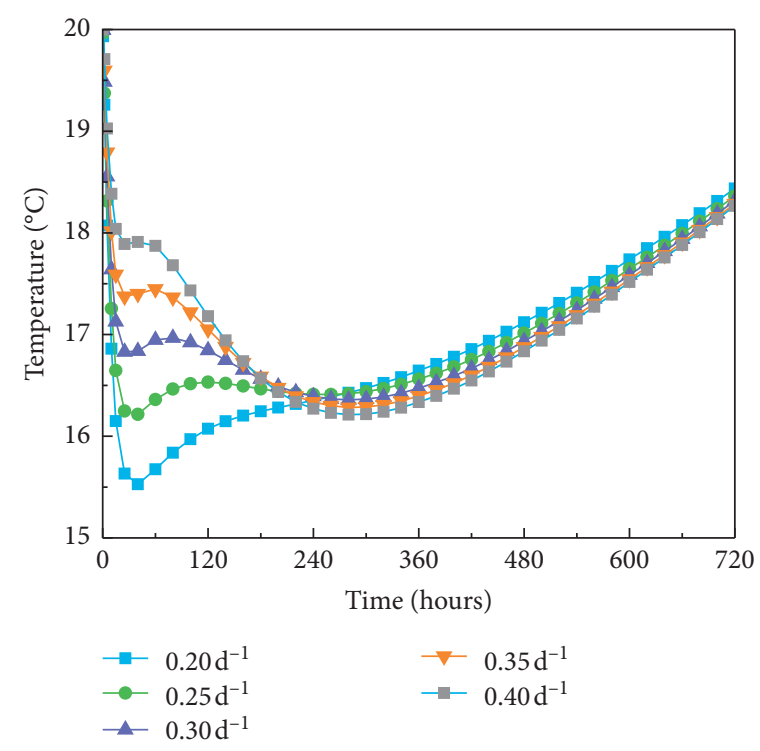

(b)

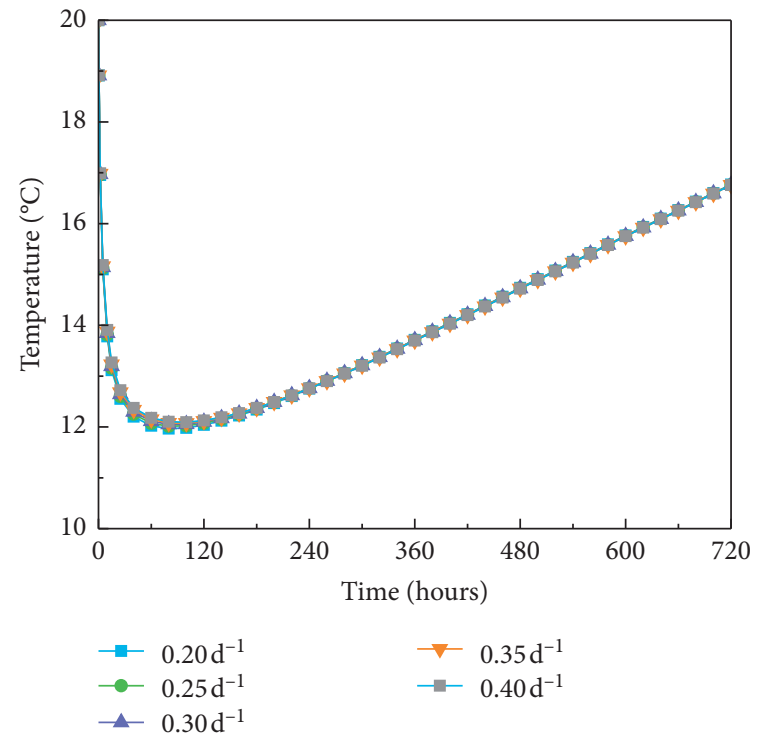

(d)

Figure 10: Temperature-time curves with different temperature rise coefficients. (a) Point A, (b) point B, (c) point C, and (d) point D.

$$
\begin{gathered}
\Delta F=\frac{A_{s}}{\beta}, \\
\Delta \bar{T}=\frac{r S}{\beta},
\end{gathered}
$$

where $A_{s}$ is the yearly amplitude of radiant heat, $r$ is the solar absorption coefficient discussed in this section, and $S$ is the solar radiation on cloudy days, which is calculated according to the solar radiation heat $S_{0}$ on sunny days. The calculation equation is given as follows:

$$
S=S_{0}(1-k n)
$$

where $k$ is the coefficient, and $n$ is the cloud cover. In this study, $S_{0}$ equals $924.5 \mathrm{~kJ} /\left(\mathrm{m}^{2} \cdot \mathrm{h}\right), n$ equals 0.1 , and $k$ equals 0.668 .

Figure 12 shows the relationship between temperature and time with six different solar absorption coefficients which are $0,0.4,0.5,0.6,0.7$, and 0.8 , respectively. The zero solar absorption coefficient is a contrast study condition. As shown in Figure 12, the solar absorption coefficient has a great impact on the temperature near the boundary of the structure but almost does not influence the core regions. The temperature arises generally linear along with the time at points $\mathrm{A}, \mathrm{B}$, and $\mathrm{C}$. Also, the bigger solar absorption coefficient induced the higher temperature rise at these three 


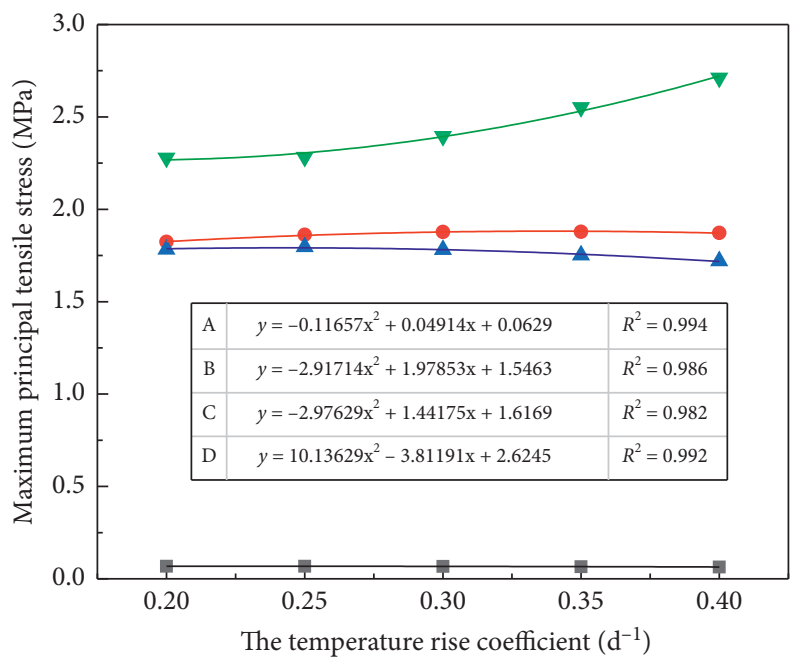

$\begin{array}{ll}\text { Calculated values } & \text { Fitted value } \\ \text { - A } & -\mathrm{A} \\ \text { - } \mathrm{B} & -\mathrm{B} \\ \text { A C } & -\mathrm{C} \\ \nabla \mathrm{D} & -\mathrm{D}\end{array}$

FIGURE 11: The calculated and fitted maximum principal tensile stress at each point with a different thermal temperature rise coefficient.
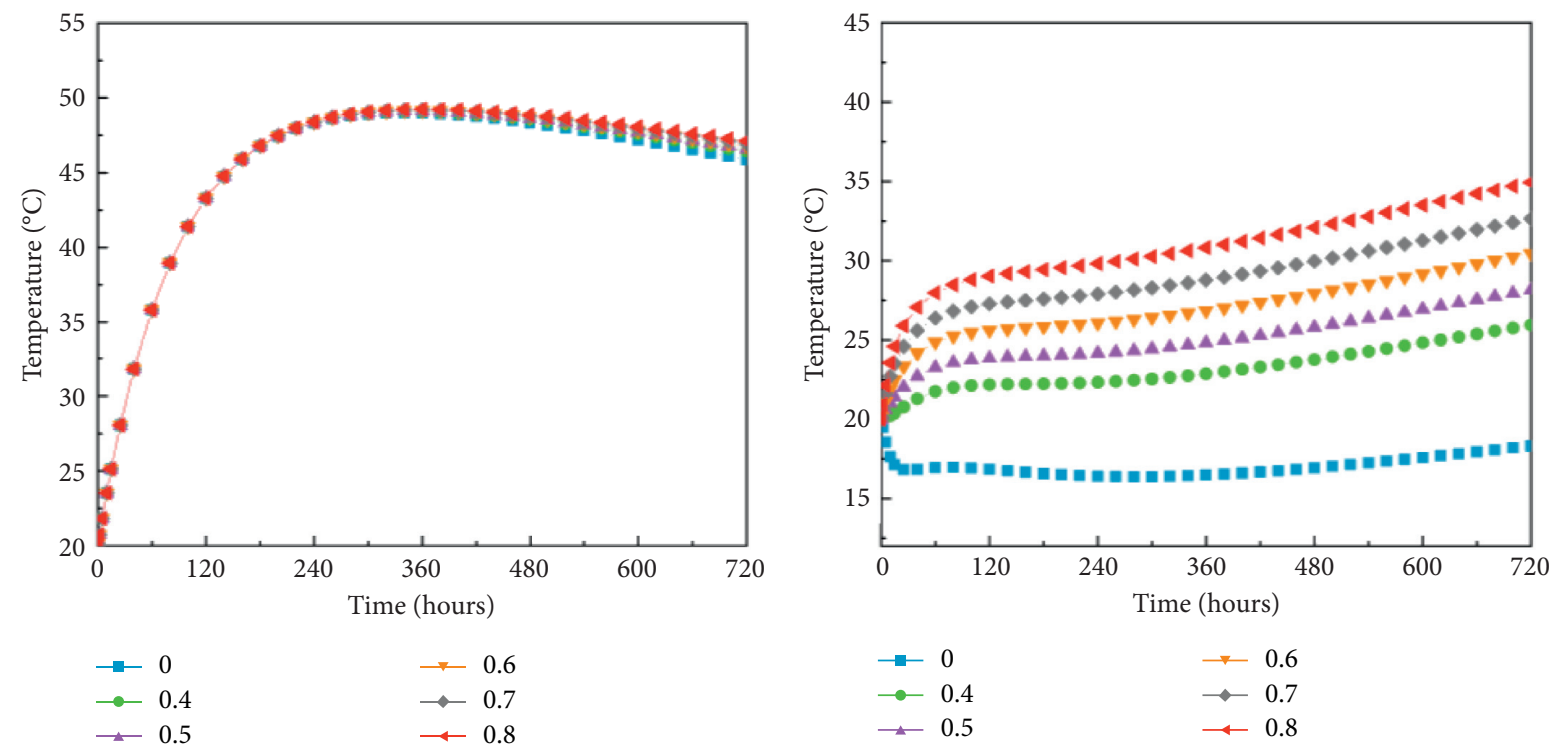

$\begin{array}{ll}\longrightarrow & 0.6 \\ \multimap & 0.7 \\ \multimap & 0.8\end{array}$

(a)

(b)

FIgURE 12: Continued. 


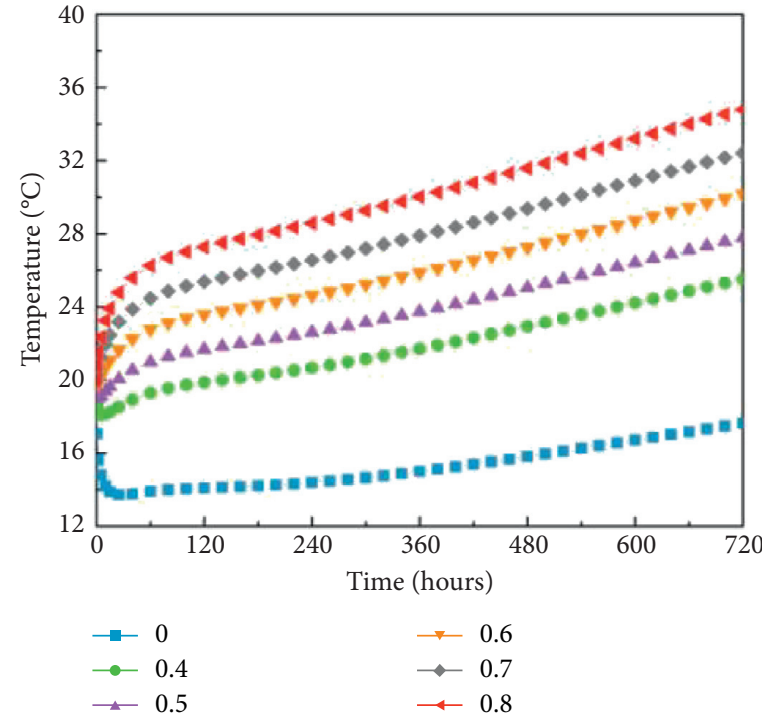

(c)

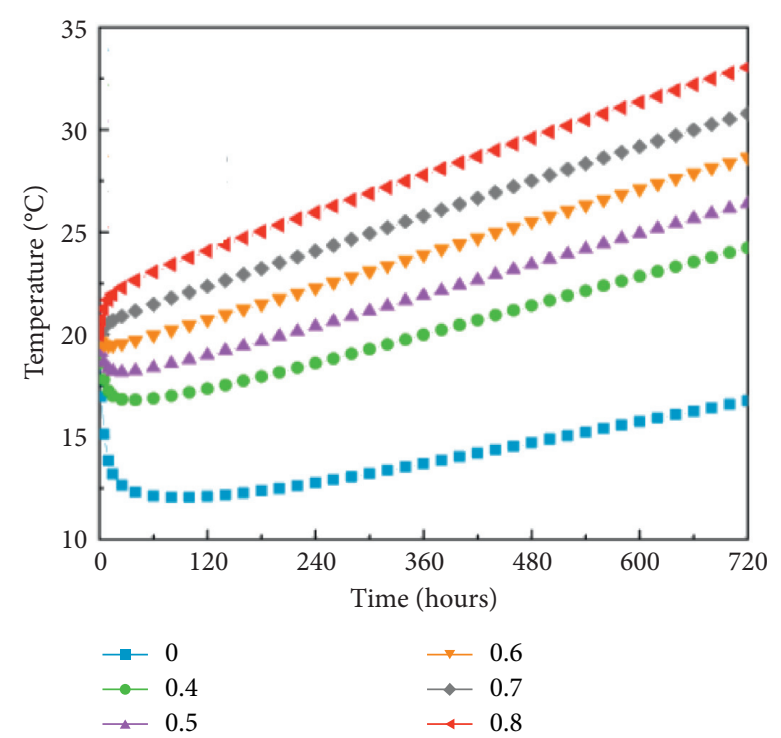

(d)

Figure 12: Temperature-time curves with different solar absorption coefficients. (a) Point A, (b) point B, (c) point C, and (d) point D.

points. The maximum temperature of point $\mathrm{A}$ is close to $49.0^{\circ} \mathrm{C}$ appeared at about 340 hours with the corresponding solar absorption coefficient. The temperature difference between the core and surface is $32.6^{\circ} \mathrm{C}, 26.3^{\circ} \mathrm{C}, 24.3^{\circ} \mathrm{C}$, $22.3^{\circ} \mathrm{C}, 20.4^{\circ} \mathrm{C}$, and $18.4^{\circ} \mathrm{C}$, respectively. It is because that more heat is induced by bigger solar absorption coefficient absorb by the surface and then against the internal heat dissipation. Therefore, it is demonstrated that the temperature difference between the core and surface reduces as the solar absorption coefficient increases.

Figure 13 shows the calculated and fitted maximum principal tensile stress at each point with a different solar absorption coefficient. It can be got that the maximum principal tensile stress of the study points all decrease to a certain degree when the solar absorption coefficient increases. However, in the matter, the maximum principal tensile stress in the structure is no more occurred at point $\mathrm{D}$, but at point $\mathrm{C}$ which is located at the surface of the structure. This conclusion just explains the common physical weathering degradation phenomenon of the construction structure. The tensile stress values at all points are less than the allowable tensile stress. Fitting the maximum principal tensile stress with the solar absorption coefficient shows a quadratic function law.

In conclusion, increasing the solar absorption coefficient can reduce the tensile stress of the concrete foundation. The maximum principal tensile stress can reduce $21 \%$ when the solar absorption coefficient changes from 0 to 0.8 . Because the solar absorption coefficient of the structure surface is related to the surface color [50], measures such as the dark coating of the surface formwork or using dark insulation can play a major role in increasing the surface solar absorption coefficient.

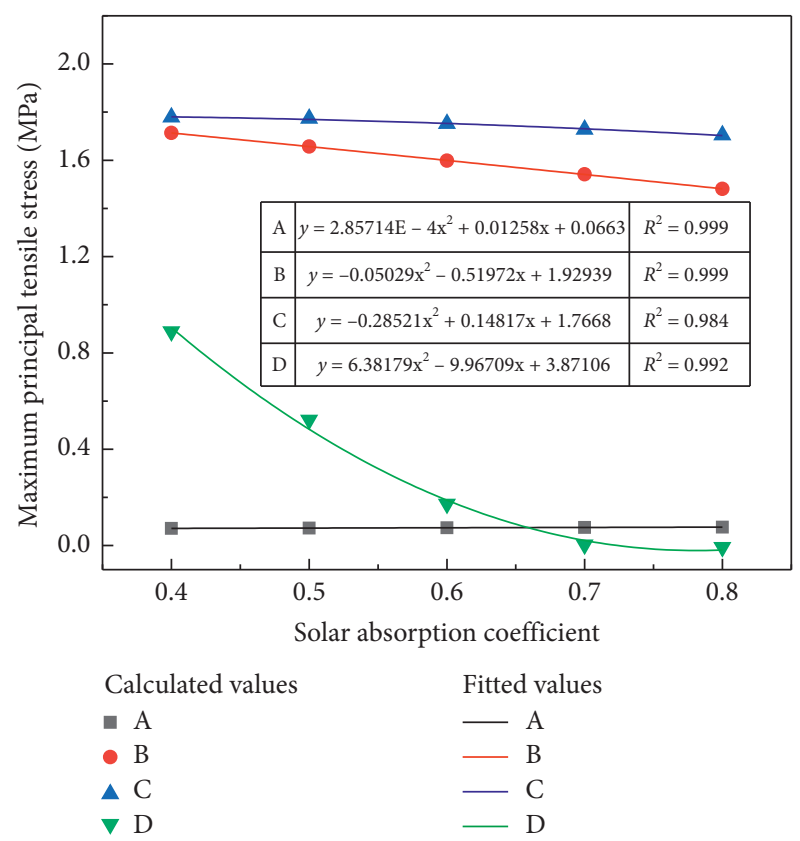

FIgURE 13: The calculated and fitted maximum principal tensile stress at each point with the different solar absorption coefficient.

4.6. Effect of Thermal Expansion Coefficient. The thermal expansion coefficient is a thermal parameter which not directly impact heat transfer but significantly influences thermal stress. Figure 14 shows the calculated and fitted maximum principal tensile stress at each point with a different thermal expansion coefficient. When the thermal expansion coefficient of concrete changes from $8 * 10^{-6} /{ }^{\circ} \mathrm{C}$ to $12 * 10^{-6} /{ }^{\circ} \mathrm{C}$, the maximum principal tensile stress at 


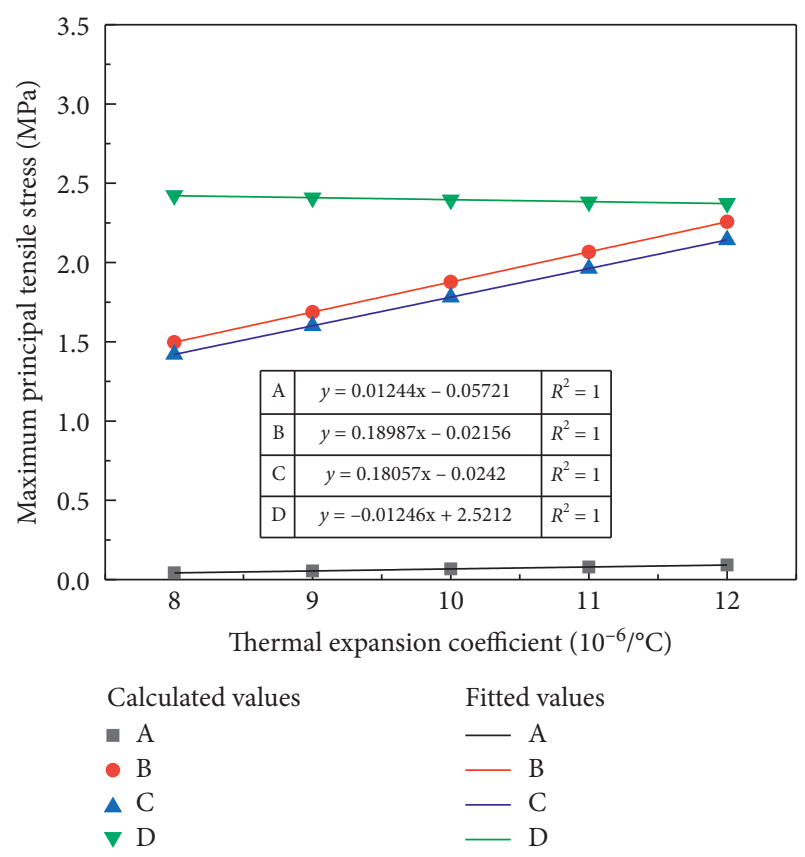

FIgURE 14: The calculated and fitted maximum principal tensile stress at each point with a different thermal expansion coefficient.

points $\mathrm{A}, \mathrm{B}$, and $\mathrm{C}$ of the structure increases with the increase of the thermal expansion coefficient while point $\mathrm{D}$ decreases. The maximum principal tensile stress of the structure also appears in the foot regions, such as point D. Fitting the maximum principal tensile stress with the thermal expansion coefficient shows a linearly relationship. The main reason is that under unconstrained conditions, the free temperature deformation is given as follows:

$$
\begin{gathered}
\varepsilon_{x}=\varepsilon_{y}=\varepsilon_{z}=\alpha T, \\
\gamma_{x y}=\gamma_{y z}=\gamma_{z x}=0,
\end{gathered}
$$

where $\alpha$ is the thermal expansion coefficient.

Equation (23) shows that the bigger the thermal expansion coefficient, the higher the deformation of the structure and also the higher stress. However, the maximum principal tensile stress at point $\mathrm{D}$ shows an opposite change rule because when the thermal expansion coefficient changes from $8 * 10^{-6} /{ }^{\circ} \mathrm{C}$ to $12 * 10^{-6} /{ }^{\circ} \mathrm{C}$, the maximum principal tensile stress of points B and C increases almost $50 \%$, and the value has quickly approached point $\mathrm{D}$. This shows that the restraint of the foundation has a certain release by stress increase of the free surface, but it releases little, so the maximum principal tensile stress of the foundation is reduced by only $2 \%$.

\section{Conclusions}

Aiming to analyze the influence of thermal parameters on the temperature and thermal stress distribution of the foundation, six thermal parameters are chosen and discussed in this study. The main conclusions are listed as follows:
(1) Increasing the thermal conductivity of concrete and reducing the specific heat and temperature rise coefficient can reduce the maximum temperature of the structure. Other thermal parameters have no obvious effect on the maximum temperature.

(2) Increasing the specific heat, solar absorption coefficient, or thermal expansion coefficient has a positive effect on reducing the maximum principal tensile stress, but on the contrary of the effect of the thermal conductivity, surface heat diffusion coefficient, and temperature rise coefficient. Moreover, it is found that fitting the maximum principal tensile stress at different positions of the structure shows a linear function with thermal conductivity, specific heat, and thermal expansion coefficient and a quadratic function with surface heat diffusion coefficient, temperature rise coefficient, and solar absorption coefficient.

(3) Combined with the research results, the following temperature control and crack prevention measures are proposed under the condition of ensuring the concrete strength, such as reducing the amount of cement, increasing the particle size of coarse aggregate, and selecting coarse aggregate with a high thermal expansion coefficient.

\section{Data Availability}

The data used to support the findings of this study are available from the corresponding author upon request.

\section{Conflicts of Interest}

The authors declare that there are no conflicts of interest.

\section{Acknowledgments}

The authors acknowledge the research funding by the National Natural Science Foundation of China (no. 41901070), State Key Laboratory of Frozen Soil Engineering (no. SKLFSE201805), Natural Science Foundation of Inner Mongolia (2017MS0106), and Hydraulic Engineering Science and Technology Project of Inner Mongolia (no. 222005176042).

\section{References}

[1] B. F. Zhu, Temperature Stress and Temperature Control of Mass Concrete, China Water and Power Press, Beijing, China, 2nd edition, 2012.

[2] H. Ding, L. Zhang, P. Zhang, and Q. Zhu, "Thermal and stress analysis of early age concrete for spread footing," Transactions of Tianjin University, vol. 21, no. 6, pp. 477-483, 2015.

[3] C. Eloísa, S. Noemí, C. Tiago, and M. L. B. Farinha, "FEA model for the simulation of the hydration process and temperature evolution during the concreting of an arch dam," Engineering Structures, vol. 174, pp. 165-177, 2018.

[4] W. C. Liu, W. L. Cao, H. Q. Yan, T. Ye, and J. Wang, "Experimental and numerical studies of controlling thermal 
cracks in mass concrete foundation by circulating water," Applied Sciences, vol. 6, no. 4, p. 110, 2016.

[5] S. Han, H. Yang, and Y. L. Wang, "Temperature control and numerical analysis for mass concrete pile cap of Haihuang bridge," IOP Conference Series: Earth and Environmental Science, vol. 153, no. 5, 2018.

[6] Y. Li, L. Nie, and B. Wang, "A numerical simulation of the temperature cracking propagation process when pouring mass concrete," Automation in Construction, vol. 37, pp. 203-210, 2014.

[7] Y. Z. Liu, J. F. Xiang, W. F. Chen et al., "Analysis of the water temperature evolution of long and narrow reservoir from impoundment to first operating period," Journal of Hydraulic Engineering, vol. 51, p. 111, 2020.

[8] X. H. He, H. Cheng, and H. X. Qin, "Study on temperature field and construction monitoring of hydration heat of railway cable-stayed bridge pile cap," Advanced Materials Research, vol. 243-249, pp. 1589-1596, 2011.

[9] J. Sun and J. Xie, "Simulation analysis of the hydration heat of large diameter CFST arch and its effects on loading age," Applied Thermal Engineering, vol. 150, pp. 482-491, 2019.

[10] Y. L. Chen, C. J. Wang, S. Y. Li, and L. J. Chen, "The effect of construction designs on temperature field of a roller compacted concrete dam - a simulation analysis by a finite element method," Canadian Journal of Civil Engineering, vol. 30, no. 6, pp. 1153-1156, 2003.

[11] H. W. Zhou, Y. H. Zhou, C. J. Zhao, and Z. Liang, "Optimization of the temperature control scheme for roller compacted concrete dams based on finite element and sensitivity analysis methods," The Civil Engineering Journal, vol. 14, no. 3, p. 116, 2016.

[12] M. H. Lee, Y. S. Chae, B. S. Khil, and H. D. Yun, "Influence of casting temperature on the heat of hydration in mass concrete foundation with ternary cements," Applied Mechanics and Materials, vol. 525, pp. 478-481, 2014.

[13] Y. Sargam, M. Faytarouni, K. Riding, K. Wang, C. Jharen, and J. Shen, "Predicting thermal performance of a mass concrete foundation: a field monitoring case study," Case Studies in Construction Materials, vol. 11, 2019.

[14] X. F. Zhang, S. Y. Li, Y. L. Li, Y. Ge, and H. Li, "Effect of superficial insulation on roller-compacted concrete dams in cold regions," Advances in Engineering Software, vol. 42, no. 11, pp. 939-943, 2011.

[15] H. F. Liu, Z. X. Shao, and H. Y. Feng, "Temperature field analysis of hydration heat of mass concrete cap," Highway, vol. 7, pp. 176-181, 2017.

[16] L. Han, X. M. Li, and Y. K. Wu, "Thermal stress analysis of concrete gravity dam based on start time," HongShui River, vol. 36, no. 5, p. 15, 2017.

[17] Y. C. Wang, Y. Hua, and C. Zhang, "Influence of different temperature control measures on crack resistance of large size concrete structure," Journal of Highway and Transportation Research and Development, vol. 36, no. 3, pp. 109-116, 2019.

[18] J. L. Chen, Z. G. Quan, and X. Peng, "Simulation analysis on mass concrete temperature field of lock floor layered pouring," Journal of Environmental Science and Engineering A, vol. 9, pp. 476-483, 2016.

[19] Y. N. Yu, W. Zhang, and Y. G. Shen, "Control measures for preventing crack on the surface of mass concrete abutment in early stage," Journal of Zhejiang University (Engineering Science), vol. 44, no. 8, pp. 1621-1628, 2010.

[20] C. H. Zhu, X. T. Li, B. J. Wang, and Y.-J. Xie, "Influence of internal curing on crack resistance and hydration of concrete," Journal of Building Materials, vol. 16, no. 2, pp. 221-225, 2013.
[21] W. Z. Jin, L. H. J. Jiang, L. Han, L. Chen, X. Yan, and C. Chen, "Influence of curing temperature on the mechanical properties and microstructure of limestone powder mass concrete," Structural Concrete, vol. 22, no. 1, 2020.

[22] C. J. Lin, G. G. Fu, and L. L. Guo, "The experimental study on controlling the hydration heat temperature field of the Zhenyuling bridge pile caps," Advanced Materials Research, vol. 594-597, pp. 1509-1515, 2012.

[23] M. X. Zhang, M. C. Li, J. R. Zhang et al., "Experimental study on electrothermal and compaction properties of electrically conductive roller compacted concrete overwintering layer in high RCC dams," Construction and Building Materials, vol. 263, p. 111, 2013.

[24] Y. X. Hiu, X. R. Sun, H. Y. Wang et al., "Effect of hydration heat temperature and cracking mechanism of beam end in early stage of T-beam," Journal of Jilin University (Engineering and Technology Edition), vol. 51, no. 3, pp. 1-9, 2020.

[25] G. B. Gao, C. X. Qian, Y. Zhuang, and C. Zhu, "Research on use of phase change materials for reduction of internal temperature rise of mass concrete," Journal of Hydroelectric Engineering, vol. 29, no. 1, pp. 197-201, 2010.

[26] L. W. Fu, J. F. Wang, W. P. Cheng, and H.-W. Xiang, "Causes and treatments of quadrate concrete pier's crack," Journal of Zhejiang University (Engineering Science), vol. 44, no. 9, pp. 1738-1745, 2010.

[27] T. Ji, G. J. Ji, and G. X. Chen, "Influence of low-heat Portland cement on properties of dam concrete," Journal of Hydroelectric Engineering, vol. 31, no. 4, pp. 207-210, 2012.

[28] J. D. Xin, G. X. Zhang, Y. Liu et al., "Environmental impact and thermal cracking resistance of low heat cement (LHC) and moderate heat cement (MHC) concrete at early ages," Journal of Building Engineering, vol. 32, 2020.

[29] Y. Huang, G. Liu, S. Huang, R. Rao, and C. Hu, "Experimental and finite element investigations on the temperature field of a massive bridge pier caused by the hydration heat of concrete," Construction and Building Materials, vol. 192, pp. 240-252, 2018.

[30] P. Y Yan, "Mechanism of fly ash's effects during hydration process of composite binder," Journal of the Chinese Ceramic Society, vol. 35, no. S1, pp. 167-171, 2007.

[31] C. Wang, C. H. Yang, J. S. Qian, M. Zhong, and S. Zhao, "Behavior and mechanism of pozzolanic reaction heat of fly ash and ground granulated blastfurnace slag at early age," Journal of the Chinese Ceramic Society, vol. 40, no. 7, pp. 1050-1058, 2012.

[32] P. Siler, I. Kolarova, J. Kratky, J. Havlica, and J. Brandštetr, "Influence of superplasticizers on the course of Portland cement hydration," Chemical Papers, vol. 68, no. 1, pp. 90-97, 2014.

[33] H. Zhao, B. Liao, F. Nian, K. Wang, Y. Guo, and H. Pang, "Investigation of the clay sensitivity and cement hydration process of modified HPEG-type polycarboxylate superplasticizers," Journal of Applied Polymer Science, vol. 135, no. 32, p. 46572, 2018.

[34] L. Wang, F. Guo, Y. Lin, H. Yang, and S. W. Tang, "Comparison between the effects of phosphorous slag and fly ash on the C-S-H structure, long-term hydration heat and volume deformation of cement-based materials," Construction and Building Materials, vol. 250, p. 118807, 2020.

[35] X. Liu, C. Zhang, X. Chang, W. Zhou, Y. Cheng, and Y. Duan, "Precise simulation analysis of the thermal field in mass concrete with a pipe water cooling system," Applied Thermal Engineering, vol. 78, pp. 449-459, 2015. 
[36] A. Tasrl and A. Susilawati, "Effect of cooling water temperature and space between cooling pipes of post-cooling system on temperature and thermal stress in mass concrete," Journal of Building Engineering, vol. 24, 2019.

[37] G. X. Zhang and Y. Liu, "Temperature control and crack prevention of super-high arch dam," Journal of Hydraulic Engineering, vol. 47, no. 3, pp. 382-389, 2016.

[38] Z. Si, D. Yang, L. Z. Huang, S. Li, and Z. Wang, "Effects of small temperature difference cooling on temperature stress of mass concrete," Chinese Journal of Applied Mechanics, vol. 35, no. 5, pp. 1146-1151, 2018.

[39] B. F. Zhu, "An implicit method for the stress analysis of concrete structures considering the effect of creep," Journal of Hydraulic Engineering, vol. 44, no. 5, pp. 40-46, 1983.

[40] H. W. Sha and T. H. De, "Thermal properties of concrete," Sichuan Water Power, vol. 5, no. 3, pp. 71-79, 1986.

[41] L. C. Wang, Z. Chang, and J. W. Bao, "Prediction model for the thermal conductivity of concrete based on its composite structure," Journal of Hydraulic Engineering, vol. 48, no. 7, pp. 765-772, 2017.

[42] J. R. Zhang, Y. Q. Zhou, J. P. Lin, and Z. Zhang, "Solar radiation affection on concrete box girder temperature effect," Journal of Tongji University (Natural Science), vol. 36, no. 11, pp. 1479-1484, 2008.

[43] Ministry of Housing and Urban-Rural Development of the People's Republic of China, GB 50496-2018, Standard for Construction of Mass Concrete, Ministry of Housing and Urban-Rural Development of the People's Republic of China, China Architecture and Building Press, Beijing, China, 2018.

[44] Y. Sargam, K. Wang, and I. H. Cho, "Machine learning based prediction model for thermal conductivity of concrete," Journal of Building Engineering, vol. 34, 2021.

[45] I. Asadi, P. Shafigh, Z. F. B. Abu Hassan, and N. B. Mahyuddin, "Thermal conductivity of concrete: a review," Journal of Building Engineering, vol. 20, pp. 81-93, 2018.

[46] Q. Y. Zhang, Test Research on the Material Property for the Face Slab Concrete of Concrete Face Dam in Cold Regions, Zhengzhou University, Zhengzhou, China, 2016.

[47] B. F. Zhu, "Critical surface heat release coefficient of concrete blocks," Water Resources and Hydropower Engineering, vol. 1, no. 4, pp. 14-19, 1990.

[48] Y. H. Liu, M. Liu, K. X. Liu, and H. W. Wang, "Research and application of single-parameter exponential $\mathrm{m}$ value of adiabatic temperature rise of concrete," Guangdong Building Materials, vol. 34, no. 2, pp. 9-12, 2018.

[49] Y. Gu, Y. D. Li, and C. R. Yao, "Research of temperature field of concrete box girder under solar radiation," Journal of Highway and Transportation Research and Development, vol. 33, no. 2, pp. 46-53, 2016.

[50] K. J. Kontoleon and D. K. Bikas, "The effect of south wall's outdoor absorption coefficient on time lag, decrement factor and temperature variations," Energy and Buildings, vol. 39, no. 9, pp. 1011-1018, 2007. 